Document downloaded from:

http://hdl.handle.net/10251/73637

This paper must be cited as:

Girard, CDP.; Rinaudo, J.; Pulido-Velazquez, M.; Caballero, Y. (2015). An interdisciplinary modelling framework for selecting adaptation measures at the river basin scale in a global change scenario. Environmental Modelling and Software. 69:42-54.

doi:10.1016/j.envsoft.2015.02.023.

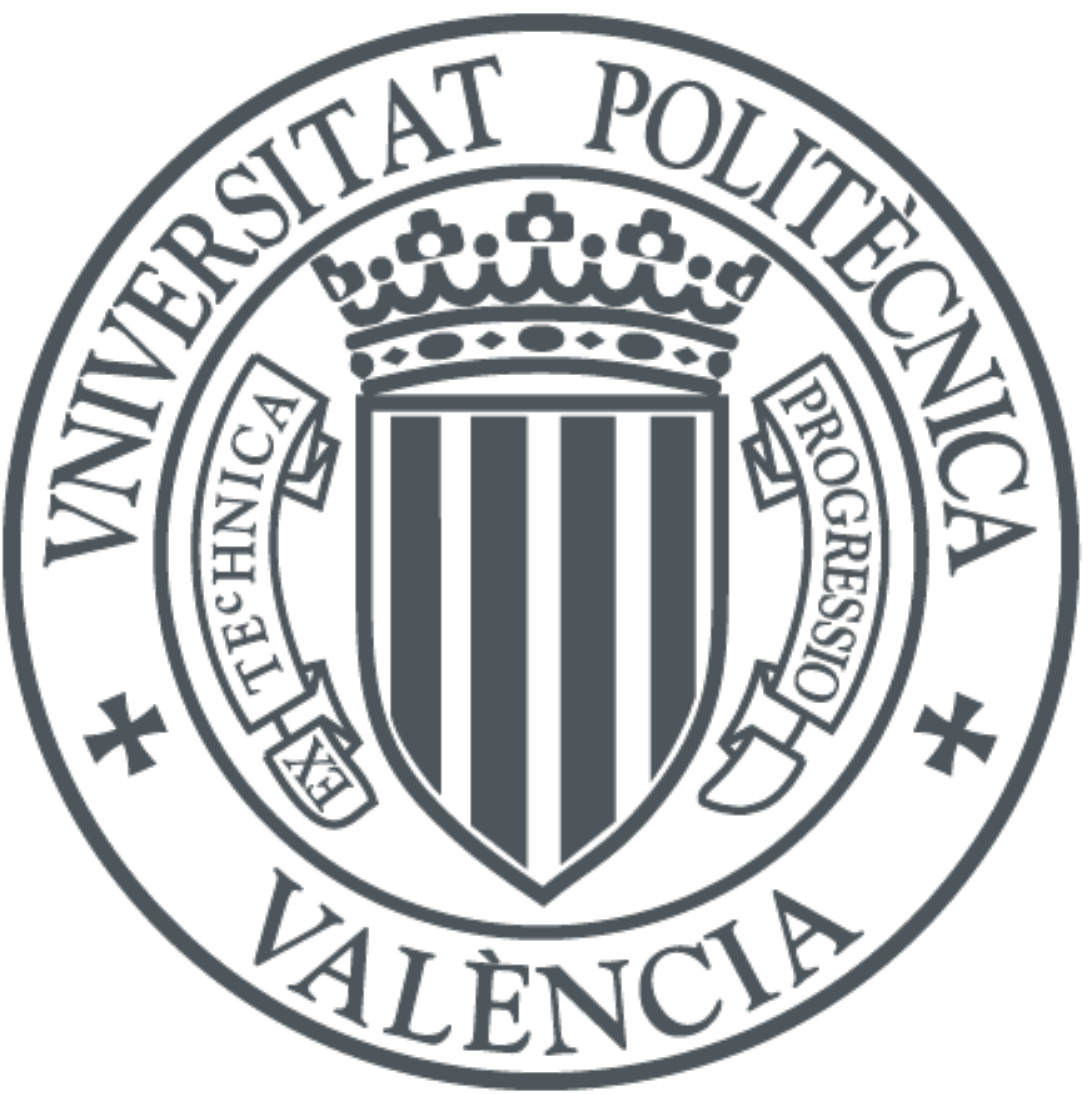

The final publication is available at

http://dx.doi.org/10.1016/j.envsoft.2015.02.023

Copyright Elsevier

Additional Information 
1

\title{
An interdisciplinary modelling framework for selecting adaptation measures at the river basin scale in a global change scenario
}

\author{
Corentin GIRARD ${ }^{\mathrm{a}}$, Jean-Daniel RINAUDO ${ }^{\mathrm{b}}$, Manuel PULIDO-VELAZQUEZ ${ }^{\mathrm{c}}$ and Yvan $^{\mathrm{N}}$
}

CABALLERO $^{\mathrm{d}}$

${ }^{a}$ Research Institute of Water and Environmental Engineering (IIAMA), Universitat Politècnica de València, Camino de Vera s/n, Valencia, 46022 Spain. cogimar@upv.es (Corresponding author)

${ }^{\mathrm{b}}$ BRGM, French Geological Survey, Montpellier, France, 1039 rue de Pinville 34000 Montpellier. jd.rinaudo@brgm.fr

${ }^{\mathrm{c}}$ Research Institute of Water and Environmental Engineering (IIAMA), Universitat Politècnica de València, Camino de Vera s/n, Valencia, 46022 Spain. mapuve@hma.upv.es

${ }^{\mathrm{d}}$ BRGM, French Geological Survey, Montpellier, France, 1039 rue de Pinville 34000 Montpellier. y.caballero@brgm.fr

\section{Highlights:}

- An interdisciplinary modelling framework is presented to analyse the effects of global change on water resource systems at the basin scale.

- Present and future urban and agricultural water demands, as well as climate change scenario, are integrated into a river basin management model.

- Future supply and demand management measures are selected using least-cost optimisation.

- Trade-offs between the cost of adaptation measures, irrigated agriculture development, and environmental requirements are quantified.

- Insights to improved integrated water management at basin scale through interdisciplinary modelling are provided.

\begin{abstract}
Shaping global change adaptation strategy in water resource systems requires an interdisciplinary approach to deal with the multiple dimensions of the problem. The modelling framework presented integrates climate, economic, agronomic and hydrological scenarios to design a programme of adaptation measures at the river basin scale. Future demand scenarios, combined with a down-scaled climate scenario, provide the basis to estimate the demand and water resources in 2030 . A least-cost river basin optimisation model is then applied to select adaptation measures ensuring that environmental and supply management goals are achieved. In the Orb river basin (France), the leastcost portfolio selected suggests mixing demand and supply side measures to adapt to global change. Trade-offs among the cost of the programme of measures, the deficit in agricultural water supply and the level of environmental flows are investigated. The challenges to implement such interdisciplinary approaches in the definition of adaptation strategies are finally discussed.
\end{abstract}

Keywords: global change; adaptation; integrated river basin modelling; programme of measures; interdisciplinary; least-cost optimisation. 


\section{Introduction}

Over the past decade, river basin agencies and stakeholders have been confronted with changing environmental, economic and societal conditions. Climatic conditions are evolving in many regions of the world, leading to increased water scarcity and risk of drought (Arnell, 2004). Climate change and the increased demand for food production lead to an extension and intensification of irrigated agriculture. Urban water use also increases due to the concentration of population in cities and the emergence of new consumption patterns (Hunt and Watkiss, 2011), particularly in the Mediterranean Basin (Thivet and Fernandez, 2012). These trends result in increasing pressure on surface and groundwater resources and dependent ecosystems. Concomitantly, societies have rising expectations in terms of environmental protection. This has materialized in many legislative frameworks, such as the EU Water Framework Directive aiming at achieving the good status of European water bodies (EU, 2000) and, more recently, the EU communication (Blueprint) to Safeguard Europe's Waters (EC, 2012) that identifies directions to achieve the good status, highlighting the interest of water efficiency measures among others.

Water planners need to anticipate how to adapt management practices and infrastructure development for some future state of their water resource systems. This requires that they develop a systemic approach depicting the natural and socio-economic factors and processes that determine future dynamics of river basins. The factors and interaction processes can be formally represented through the development of integrated river basin management models (Jakeman and Letcher, 2003; Letcher et al., 2007), which can be used either to learn about the impact of alternative water management strategies or to identify optimal strategies under future climate, demand and regulatory scenarios.

Developing such integrated models to estimate future changes and frame adaptation plans is not, however, a trivial task. It requires integrating concepts, methods and modelling tools from various domains of expertise and scientific disciplines. For instance, forecasting future urban water demand (Baumann et al., 1997) might require the participation of demographers (population growth forecasts), urban planners (housing stock and characteristics), economists (impacts of changing tariffs, changes in economic activities) and engineers (water supply and water saving options). Similarly, forecasts of future change of agricultural irrigation water demand should be informed by an economic analysis of future agricultural and international trade policies (economics and political science); by a technical assessment of innovations likely to emerge in terms of crop varieties, cropping practices and irrigation techniques (engineering sciences); by modelling crop water requirements (agronomy) under changing climatic conditions (Rinaudo et al., 2013a); and by a stakeholder analysis (sociology) to infer the objectives, priorities, expectations, behaviour and needs of the different agricultural stakeholders.

Modelling complexity also comes from the imperative to support decision making in a context where heterogeneous stakeholders participate in the search for a negotiated solution, moved by different interests and multiple objectives. Involving the stakeholders in the development of the model or some 
of its components theoretically ensures a better understanding of the underlying assumptions, thereby increasing its acceptability and credibility. However, the complexity of models, and the associated uncertainty, can be such that it stretches the understanding capacity of many stakeholders. A common issue among all the modelling tools and methods developed to address water management issues is indeed the one of uncertainty and its propagation that challenges the capacity of scientists to accurately represent the reality and provide reliable information about the future (Refsgaard et al., 2007).

Sustainable management of water resources and dependent ecosystems requires an understanding of climate change impacts on river flows (Caballero, et al. 2007) and groundwater levels (hydrology and hydrogeology), and on the aquatic environment (hydro-ecology). Last but not least, a crossfertilization of engineering, economics and other sciences is needed to define complex adaptation strategies that involve new combinations of water demand management measures (e.g. water conservation measures), infrastructure operation (e.g. management of reservoir or irrigation systems) and development of new capacity (e.g. groundwater exploitation or desalination projects). Therefore, we would expect an interdisciplinary modelling approach to provide the most relevant insights to water managers and policy makers. Combined with the participatory process, interdisciplinary modelling can help to develop a shared understanding of the water problems as a foundation for negotiated management and policy solutions (Heinz et al., 2007). Indeed, the integration of knowledge from different disciplines beyond their respective paradigms and the interconnection of mondisciplinary intellectual silos has been highlighted as one of the salient dimensions for the success of integrated modelling approaches (Hamilton, et al. 2015).

Pioneering efforts to develop an interdisciplinary approach addressing water planning issues date back to the Harvard Water Program in the late 1950s, when economics, social sciences and engineering were first brought in to support water policy making. Nowadays, such initiatives have become even more necessary due to the growing complexity of water management issues (Reuss, 2003). River basin management models - often coupled with Decision Support Systems tools - have been developed at basin scale to assess the performance of water resource systems under different scenarios and policy strategies (Andreu et al., 1996; Labadie, 2004). More recently, hydro-economic models (HEM; Harou et al., 2009) took one step further into interdisciplinary modelling by integrating economics and water resources management into a coherent framework. At basin scale, HEMs have been applied to assess the marginal economic value of storage and environmental flows and so provide economic indicators and instruments, as required by the EU WFD (Pulido-Velazquez et al., 2008 and 2013; Riegels et al., 2013). In Europe, they are expected to assist in recommending measures for the next round of EU water policy (De Roo et al., 2012). In the United-States, HEMs have been applied to analyse the adaptation of inter-tied water supply system to global change in California (Tanaka et al., 2006; Medellin-Azuara, et al., 2008) and New Mexico (Hurd and Coonrod, 2012). Various research initiatives have been launched to integrate the impact of climate change, from an interdisciplinary perspective, into the implementation process of the WFD (Quevauvillier et al., 2012; Pouget et al., 
2013). However, despite a few pioneering studies, the vast majority of existing studies stop short at the impact assessment stage, which means they provide only a limited contribution to the question of adaptation (Wilby and Dessai, 2010).

In the literature, the issue of selecting measures for the planning of water resources has been long addressed as the problem of capacity expansion optimization (planning and scheduling of infrastructure over time) through least-cost optimization models (O'Laoghaire 1974, Loucks et al. 1981; Ejeta and Mays, 2004, Mastrosov et al. 2013). From this perspective, the part of the framework presented dedicated to the selection of measures could be seen as a least-cost planning model without option scheduling. Indeed, we consider that the main focus of the work is located one step before the scheduling in the planning process. The framework presented clearly deals with the definition of the planning scenarios (demand and hydrological) and objectives (environmental flows, agricultural development) before the phasing of the investment. The added value of the contribution lies in the combination of different modelling disciplines to define the climate and demand change scenario, and then assess trade-offs between the cost of the programme of measures and other planning objectives at the river basin scale.

This paper presents an interdisciplinary modelling framework to select adaptation measures at riverbasin scale in a global change scenario. The method is tested on the Orb river basin, a Mediterranean basin in Southern France, where global change is expected to exacerbate the difficulties of meeting the growing water demands and the WFD environmental in-stream flow requirements. We describe first the general modelling framework that is used to generate future global change scenarios, to assess the impact of global change and to design the Programme of Measures (PoM) at basin scale; this is followed by a description of the demands and water resources modelling, and of the selection of adaptation measures through a Least-Cost River Basin Optimisation Model (LCRBOM). Next, we introduce the case study of the Orb basin, and describe the future socio-economic and environmental scenarios applied. One single scenario is selected to illustrate the application and potential of the framework. The results quantify future deficits in the supply of agricultural demand, and identify where adaptations to global change are required. Trade-offs between cost of the adaptation measures, agricultural deficits and environmental flow requirements are finally evaluated to highlight the potential of the interdisciplinary modelling framework to support water resources management. The final section presents the limitation of the models and discusses potential future developments, with feedback on the interdisciplinary process.

\section{Material and methods}

\subsection{Interdisciplinary modelling framework}

Because the interdisciplinary modelling framework presented in this paper is aimed at planning, the first challenge consists of identifying the main variables that determine the future of the system and, 
and then in mobilizing and coordinating the corresponding disciplines able to model the processes impacting these variables. Figure 1 depicts the interdisciplinary modelling framework we adopted and the variables chosen for our case study - a catchment that is fairly representative of those located on the northern rim of the Mediterranean basin. It shows that the water deficit-to be minimised in the future through adaptation measures - depends not only on climatic change but also on a range of socio-economic variables. This conceptual framework was used as a basis for combining different modelling approaches in a computer-based integrated river basin management model. While a number of relationships were formally represented using mathematical models, other relationships were assessed using more qualitative and participatory methods (eg. for building the agriculture demand scenario using participatory workshops).

Water demand models were developed to integrate the most likely evolution of urban and agricultural water uses. The urban water demand model $\mathbf{1}$ is based on an econometric model combined with a population and housing stock forecast model that is based on regional statistical data. The agricultural water demand model 2 combines an agronomic model and scenario workshops involving stakeholders. Climate change impact on local temperatures, evapotranspiration and precipitation is determined using downscaled results from a General Circulation Model (GCM) 3 . The consequences of climate change on agricultural water requirements are taken into account based on the previous agronomic model, while its consequences on natural river flow regimes are considered using hydrological simulation models 4 . Minimum in-stream flow requirements were derived from existing estimates using a hydraulic habitat model complemented by local expertise $\mathbf{5}$. The water resources system is conceptualized as a flow network of nodes and links 6 . The most important surface reservoirs are included as storage nodes $\boldsymbol{\nabla}$, and the inter-basin water transfers as network links. Reservoir releases and the volume of water to be supplied are defined through an optimisation procedure for a particular time horizon and spatial network. A catalogue of adaptation measures was identified based on stakeholders' workshops $\boldsymbol{8}$ and engineering studies $\boldsymbol{9}$. These measures were characterized in terms of effectiveness (defined as a volume of water) and cost (defined as an annualized investment with operating costs) (10 . Finally, the least-cost river basin optimisation model (11) identifies the optimal portfolio of adaptation measures to minimise the agricultural deficit at minimum cost. Further details are provided on the major components of this interdisciplinary modelling framework in the following sections. 
Figure 1: Interdisciplinary modelling framework to assess global change impacts and frame adaptation at river basin scale

\subsection{Demand scenarios}

\subsubsection{Urban demand scenario}

The urban water demand forecasting model 1 combines an econometric model, which predicts per capita water consumption (Rinaudo et al., 2012) with a population and property forecast model based on regional statistical data (Vernier and Rinaudo, 2012). The econometric model allows simulation of the impact of changes in the socioeconomic variables (water tariffs, income). It calculates urban water demand for 2008 (Baseline) and 2030 (Future) planning horizons for all the municipalities (Urban Demand Unit, UDU) that abstract water from the water resources system. One key element of the method is the adjustment of the domestic demand ratio to different explanatory variables in each UDU: the price of water, average household income, climatic conditions, and the opportunity to drill their own well.

\subsubsection{Agricultural demand scenario}

The agricultural scenario was developed with the participation of stakeholders, following a method developed by Rinaudo et al., (2013a). This method combines scenario workshops and modelling tools to assess future agricultural water demand in a three-step process. First, irrigated areas were estimated by crop and irrigation district (Agricultural Demand Unit, ADU) for a baseline year, according to the last general agricultural census in 2010. Then, a plausible future scenario was constructed for the 
planning horizon (2030) based on assumptions about how the main drivers of agricultural development will evolve at global (EU-Common Agricultural Policy, market prices, technical innovation, etc.) and local scale (land use policy, sector development). The assumptions were validated by semi-structured interviews and focus group discussions with local experts (Maton et al., 2012).

\subsection{Assessing climate change impact on demands and available resources}

\subsubsection{Climate change scenario}

Future climate 3 was assessed using downscaled data from the GCM ARPEGE CNRM-CM3 (SalasMelia et al., 2005) forced by the A1B emission scenario, which is considered a median scenario amongst all possible future ones (Bates et al.,2008). The downscaled scenario was provided as part of the SCRATCH 2010 experiment, based on a statistical "weather type" downscaling method (Pagé and Terray, 2010). The downscaled precipitation (P) and potential evapotranspiration (PET) time series are representative of the baseline (1971-2000) and the so-called 'mid-term future period' (2046-2065). They are provided at a daily time step, with a spatial resolution of 8 by 8 kilometres, identical to the scale of historical meteorological data used to drive water demand and hydrological models (Vidal et al., 2010).

\subsubsection{Impact of climate change on agricultural demand}

It is expected that irrigation water requirements for agricultural crops in this area will be impacted by climate change. This impact was assessed using an agronomic model 2 (Hoang et al., 2012), adapted from Allen, et al. (1998). The model calculates Agricultural Water Demand (AWD) with a 10-day time step as the water required by the crop, in addition to rainfall, to compensate for evapotranspiration, taking available soil moisture into account. Inter-annual monthly average demands are estimated for the baseline and future periods. For each irrigation district (i), Eq. (1) calculates the Crop Water Requirement (CWR) of crop (j) associated with an irrigated area $\left(\mathrm{A}_{\mathrm{i}, \mathrm{j}}\right)$, which is a function of the meteorological variables $\left(\mathrm{PET}_{\mathrm{i}}\right.$ and $\left.\mathrm{P}_{\mathrm{i}}\right)$, available soil moisture $\left(\mathrm{SM}_{\mathrm{i}}\right)$, a crop coefficient $\left(\mathrm{Kc}_{\mathrm{j}}\right)$, and an irrigation efficiency parameter $\left(\mathrm{E}_{\mathrm{i}, \mathrm{j}}\right)$.

$$
A W D_{i, t}=\sum_{j} E_{i, j} \times A_{i, j} \times\left(E T P_{i, t} \times K c_{j, t}-P_{i, t}-S M_{i, t}\right) \quad \forall i, t \quad \text { (Eq. 1) }
$$

\subsubsection{Impact of climate change on the hydrology}

Climate change is also expected to perturb the hydrological regime. To assess this impact in our case study (section 3), the hydrological modelling framework 4 follows a three-step process for each of the sub-river basins defined. The first step was to restore the natural flow regime of the sub-basin by 
adding urban and agricultural water withdrawals to the observed monthly river discharges (Chazot, 2011; Vier and Aigoui, 2011). Then, a monthly, two-parameter rainfall-runoff model (GR2M, Mouelhi et al., 2006) was calibrated and validated using historic precipitation, PET and flow data for each sub-basin (Caballero and Girard, 2012). The Root-Mean-Square Error (RMSE) was used to automatically calibrate the model by means of optimisation. The validation/calibration performances of the model were assessed using the Nash and Sutcliffe (1970) efficiency in addition to the RMSE ${ }^{1}$. The results of the calibration and validation of the hydrological models are considered good enough to assess the impact of climate change in water resources, more details on the calibration and validation are presented in Appendix C.

\subsection{Assessing agricultural deficits}

In a business-as-usual scenario (BAU) with no adaptation measures, water deficits are likely to appear in the future, due to a combination of increased water demand and reduced hydrological flows. Assuming that the existing regulatory framework is maintained, that deficit would mainly be borne by agriculture. Urban demand, legally defined as the highest priority use, would be satisfied first. Then, environmental flows should be guaranteed, while agriculture would only be authorized to use the remaining water available.

Performance of water resources systems is usually assessed using indicators, such as reliability, resiliency and vulnerability criteria (Hashimoto, 1982; Loucks, 1997). In our case, we adapted the Demand Reliability Index (DRI) (Martin-Carrasco, et al.,2013), which quantifies the reliability of a system to satisfy demands, by computing the ratio between the demand satisfied for a given acceptable level of reliability and the total annual demand. French legislation requires all demands to be fully supplied in at least 4 out of 5 years, giving priority to urban use and environmental requirements over agricultural use (MEEDDT, 2008). This allows a deficit in the supply of agricultural demand with a return period $\mathrm{T}$ of 5 years (5-year deficit). In other words, this corresponds to supplying the full agricultural annual demand with a level of reliability (noted $r)$ of $80 \%(r=(1-1 / T) \times 100)$. In accordance with this requirement, we defined an Agricultural Deficit Index (ADI) to characterize the degree of failure of the system to meet this acceptable 5-year deficit. The ADI is the ratio between the maximum annual deficit that occurs with a return period $T^{*}$ less than $T$ equal 5 years $\left(T^{*}<\mathrm{T}=5\right)$ and the annual demand of a given ADU (Eq. 2).

$A D I_{T^{*}}^{a}=\left(1-S_{T^{*}}^{a} / \operatorname{Dem}^{a}\right) \times 100$

Where $\mathrm{ADI}_{T^{*}}^{\mathrm{a}}$ is the Agricultural Deficit Index for the agricultural annual demand at the ADU "a" associated with a return period $\mathrm{T}^{*}$ lower than the acceptable value $\mathrm{T} ; \mathrm{S}_{T^{*}}^{\mathrm{a}}$ is the minimum annual water

\footnotetext{
${ }^{1}$ Nash-Sutcliffe efficiency is a criterion for quantifying models performance in comparison to the observed values (relative measure) and therefore, it allows comparison with other models, whereas the root mean square error characterizes only the performance in absolute values (Pushpalatha et al. 2012).
} 
supplied to the ADU "a" in $\mathrm{Mm}^{3}$ per year, with a return period $\mathrm{T}^{*}$; Dem ${ }^{\mathrm{a}}$ is the annual demand at the $\mathrm{ADU}$ "a", in $\mathrm{Mm}^{3}$ per year. An ADI equal to 0 means that the system fulfils the legal requirements of having no more than a 5-year deficit; if this condition does not hold (ADI greater than 0 and up to 1), the index quantifies the magnitude of the greater than acceptable deficit in comparison to the annual demand.

\subsubsection{River basin optimisation model}

First, a river basin optimisation model 6 was developed to represent water allocation in the basin and to estimate the deficit in the present baseline and the BAU future scenarios, integrating the demand and hydrological scenarios previously defined (Section 2.2 and 2.3). The model minimises agricultural deficit with a return period of less than 5 years, with a monthly time step (objective function, Eq.3), by optimising reservoir management and water allocation (decision variables) over the time horizon. Meanwhile, water allocation has to meet the environmental requirements and the target supplies for the urban demands in order of priority.

Minimize $\prod_{D}=\sum_{t} \sum_{a} D e f_{a, t}^{T^{*}}$

Where, $\mathrm{t}$ is the time step index (monthly); "a" is the index of the ADU, and $D e f_{a, t}^{T^{*}}$ is the deficit for ADU "a" at month " $\mathrm{t}$ " with a return period $\mathrm{T}^{*}$ less than $\mathrm{T}$. Additional equations are presented in Appendix B.

The sub-river basins are represented in a flow network of nodes (diversions and/or storage nodes), linked by arcs that represent the river stretches. UDUs and ADUs are connected to the corresponding nodes of the sub-basin from which they abstract or return water. At each node and for each monthly time step, constraints are imposed on demand targets, minimum environmental flow requirements, and reservoir operating rules for both flood protection and dead storage volume. If less water is available than is needed to meet the constraints, there will be a deficit in the water available to supply agricultural demand. Optimisation is carried out over a monthly flow time series, first on the baseline period (1971-2000) and then for the global (climate and demand) change scenarios corresponding to the future period (2046-2065). The model was implemented using GAMS (General Algebraic Modelling System, Rosenthal, 2012) and applying Mixed Integer Programming with the CPLEX solver.

\subsubsection{Environmental flow requirements}

In-stream environmental flow requirements 5 aim at maintaining the environmental functions of the river by means of an appropriate flow regime (Postel and Richter, 2003). Ideally, a seasonally variable flow regime is needed to sustain freshwater ecosystems (Poff et al., 1997). However, the current approach applied in the river basin defines only minimum in-stream flow requirements for selected nodes. A hydraulic method (Gippel and Steardson, 1998) using the habitat method ESTIMHAB 
(Lamouroux, 2002) was applied by Vier and Aigoui (2011) to define minimum flow thresholds at each node of the basin.

\subsubsection{Infrastructure management}

The reservoir is managed as a multipurpose reservoir. Operating rules fix only the monthly deadstorage and maximum volume of the reservoir for flood protection (Chazot, 2011). The volume released from the reservoir and the volumes of water allocated are defined during the optimisation procedure. Direct evaporation from the reservoir has been calculated based on estimates of average annual reservoir evaporation in the south of France (Vachala, 2008).

\subsection{Selecting least-cost adaptation programme of measures}

Once the deficits are calculated for the present and future periods, the river basin optimisation model is converted into a least-cost river basin model that minimises the cost of a programme of adaptation measures (given the operational and physical constraints of the water resources system), which include supplying agricultural and urban demands, and meeting the environmental flow targets. The catalogue of potential adaptation measures consist of capacity development projects and water conservation measures that could be implemented in the different UDUs and ADUs of the system.

\subsubsection{Identification and assessment of adaptation measures}

Workshops with local stakeholders were held to identify possible adaptation measures to cope with increased water deficit in the basin, which were then documented by a series of complementary technical studies. Water conservation measures $\mathbf{8}$ are considered at the level of UDU (municipality or group of municipalities) and ADU (irrigated area) to define a set of local adaptation measures. For each unit, we estimated the volume of water that could be saved by implementing these measures. The equivalent annual cost of the measures was calculated by applying a $4 \%$ discount rate on investment and operating costs 10 .

In terms of capacity expansion measures 9 , a specific study was carried out to identify aquifers unconnected to the river (Rinaudo et al., 2013b) that could be sustainably used by drilling new wells. The sustainable yield and costs (investment, operation and maintenance) associated with the projected wells were estimated. The catalogue of measures includes the possibility of building a desalination plant to supply coastal municipalities. Investment and operating costs for such plants were estimated based on figures provided by local engineering companies and cross-checked with values reported in international surveys (Zhou and Toll.,2005; Ghaffour et al.,2013). 
The LCRBOM (11 was built onto the previous optimisation model (section 2.4.1). The objective function (Eq.4) minimises the total annualized cost of the measures applied to meet urban and agricultural demands and minimum in-stream flow constraints. For that purpose, measures are selected to reduce the deficit in agricultural demand (Eq. 4 and 5).

Minimise $\Pi=\prod_{C}+M \times \prod_{D}$

Where: $\prod_{D}$ is defined in Eq. 3; $M$ is a very large positive number that is higher than the sum of the cost of all the other measures.

$\prod_{\mathrm{C}}=\sum_{\mathrm{m}} \operatorname{Act}(\mathrm{m}) \times \operatorname{Cost}(\mathrm{m})+\sum_{\mathrm{t}} \sum_{\mathrm{m}} \mathrm{V}(\mathrm{m}, \mathrm{t}) \times \mathrm{V} \operatorname{Cost}(\mathrm{m}) / N$

where, $\mathrm{m}$ is an index of the measures of urban or agricultural demand, groundwater or desalination project; $\mathrm{t}$ is the time step index (monthly); $\operatorname{Act}(\mathrm{m})$ are binary decision variables of the measures $\mathrm{m}$; Cost is the fixed equivalent annual cost $(€)$ of the measures, $\mathrm{m} ; \mathrm{V}$ is the volume of water in $\mathrm{Mm}^{3} /$ month coming from the groundwater and desalination measures, respectively; VCost is the variable costs of the groundwater and desalination measures in $€$ per $\mathrm{Mm}^{3}$ per month; $\mathrm{N}$ is the total number of years of optimisation; Additional equations are presented in Appendix B.

The supply and demand management measures are characterized by their cost and effectiveness for each ADU and UDU. By introducing slack variables with a very high cost (far beyond the range of costs of the measures) in the objective function, the model avoids unfeasible cases in which implementation of every measure is insufficient to avoid a deficit in agricultural water supply.

\section{Case study and future scenarios}

\subsection{Case study description}

The modelling framework was implemented for the River Orb basin $\left(1580 \mathrm{~km}^{2}\right.$-Figure 2), located on the French Mediterranean coast. The Mediterranean region is projected to be affected by climate change, and has been defined as a "hot spot" on a global scale (Giorgi and Lionello, 2008; Mariotti et al., 2008), where severe impacts on water resources are likely (Bates et al., 2008). The catchment is characterized by a Mediterranean climate and hydrological regime with significant low flows in summer and flash flood events in autumn. The average annual natural flow is $850 \mathrm{Mm}^{3}$. While rainfall is abundant in the hilly upstream area (1800 mm per year), it is much scarcer in the coastal area (570 $\mathrm{mm}$ ), where most of the population, agriculture, tourism and other economic activities are located. The River Orb and its alluvial aquifer form the main resources for supplying urban areas with drinking water. Traditional gravity channel irrigation systems also depend on these resources to irrigate crops in the upstream part of the catchment (1000 ha). A more efficient and larger pressurized system, developed in the 1960s, supplies irrigation water to agriculture in the coastal plain (5000 ha). River 
flows are regulated by the Mont d'Orb multipurpose reservoir $\left(30.6 \mathrm{Mm}^{3}\right.$ of usable capacity, with a mean annual inflow of $101.8 \mathrm{Mm}^{3}$ ). It was constructed to store water for irrigation downstream and is also used to protect against flood risk. It is only marginally used to produce hydropower.

At present (baseline situation), urban and agricultural water demands represent $62 \%$ and $38 \%$ of total water demand, respectively, in an average climatic year. With a demand to resources ratio of less than $20 \%$, the total demand for environmental requirements and consumptive use falls within the available annual water resources during a dry year (Table 1). Under baseline conditions, the annual balance of supply and demand at basin scale is satisfactory. However, the allocation of scarce water resources becomes an issue during the summer, for both baseline and future periods. We calculated the available water resources for the 5-year low-flow for an annual or summer period (mid-May to mid-September). The environmental requirements and demands for consumptive uses approach the level of available natural resources during these periods $(60 \%)$ and the demands are likely to exceed available resources in future summer periods (125\%, for the considered climate scenario). Notwithstanding, this initial balance of resources and demand does not consider the inter- and intra-annual regulation provided by the reservoir, as is the case with the river basin management model developed in this study.

The river basin authority has already classified the water bodies of the Orb river basin as being at risk of failing to meet the good quantitative status required by the WFD (AERMC, 2009). The two most recent water management plans for the River Orb states the improvement of quantitative water resources management as one of its main objectives (SMVO, 2013).

\begin{tabular}{|c|c|c|c|c|c|c|}
\hline Demand $\left(\mathrm{Mm}^{3}\right)$ & Urban & Agricultural & Environmental & Total & $\begin{array}{c}\text { Resources } \\
\left(\mathrm{Mm}^{3}\right)\end{array}$ & $\begin{array}{c}\text { Demand/resources } \\
(\%)\end{array}$ \\
\hline Baseline & 19.2 & 11.6 & 43.0 & 73.8 & $374^{\mathrm{b}}$ & $19.7 \%$ \\
\hline $\begin{array}{l}\text { Baseline } \\
\text { summer }^{\mathrm{a}}\end{array}$ & 7.8 & 10.8 & 14.5 & 33.1 & $55^{\mathrm{b}}$ & $60.2 \%$ \\
\hline Future & 21.9 & 28.3 & 43.0 & 93.2 & $276^{b}$ & $33.7 \%$ \\
\hline $\begin{array}{c}\text { Future } \\
\text { summer }\end{array}$ & 8.9 & 27.1 & 14.5 & 50.5 & $40.4^{\mathrm{b}}$ & $125 \%$ \\
\hline
\end{tabular}

Table 1: Annual and summer water balance of the Orb river basin baseline and future scenarios 


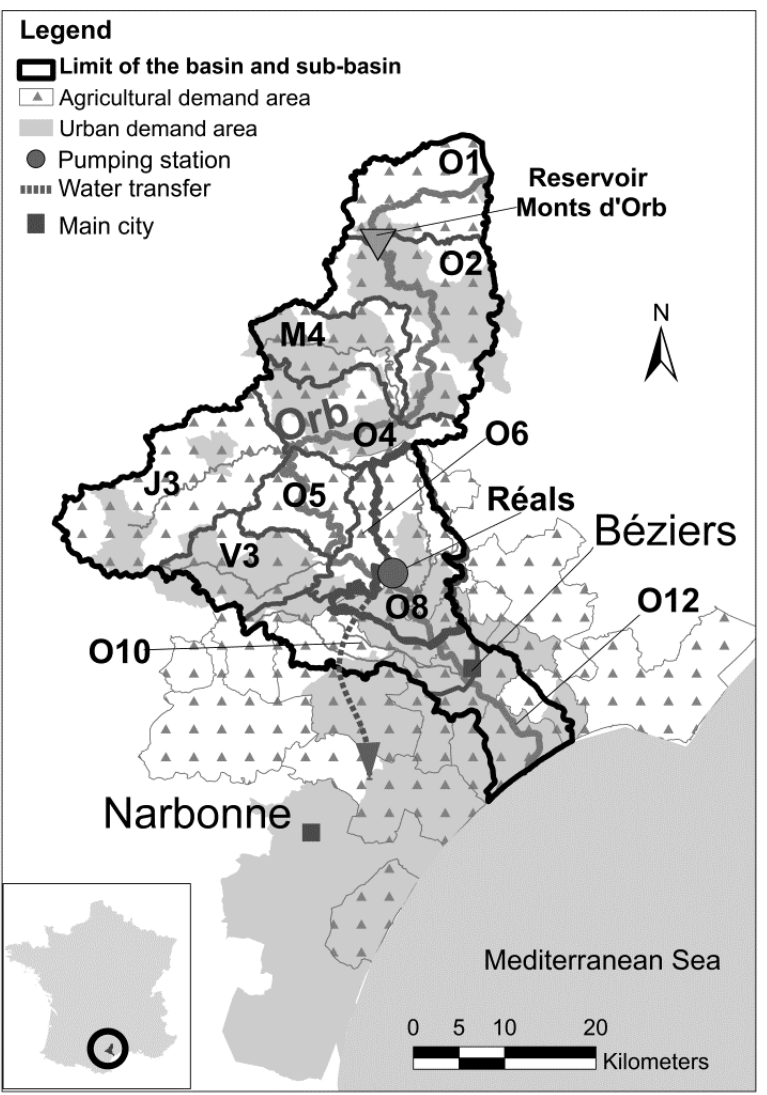

Figure 2: Case study area: the Orb river basin

\subsection{Future demand scenarios}

Change in future urban water demand is mainly driven by population growth $(1 \%$ per year, on average). Per capita consumption is forecasted using the econometric model (section 2.2.1). Over the 2008-2030 period the following assumptions were made: 1) a $30 \%$ increase in water prices and a 10 $\%$ decline in per capita consumption, due to technological change, 2) a stable household income and 3) a $6 \%$ increase of per capita consumption due to climate change (mainly due to swimming pool evaporation and lawn watering) (Table 3). Overall, urban water demand is expected to increase by 14 $\%$ between the baseline and future periods.

Agricultural demand is expected to increase at a much faster pace during the same period due to the combined effect of an increase in irrigated area and a rise in the evapotranspiration rate (section 2.2.2). Stakeholders who participated in the definition of the future agricultural development scenarios envisaged a significant development of irrigation practices within the existing vineyards (Table 2), as a way to secure the harvest in case of drier summers, due to a combination of regulatory, economic, and technical changes. Climate change will certainly exacerbate this trend. The marginal (and combined) effects of changes in irrigated area and climate are depicted in Figure 3. Climate change alone would increase demand by $58 \%$ (considering that the crops grown and the area under irrigation 
remain unchanged). Socio-economic change alone would result in a $64 \%$ increase. When combined, the two drivers result in a $145 \%$ increase in irrigation water demand.

\begin{tabular}{cll}
\hline Demand & \multicolumn{1}{c}{ Urban } & \multicolumn{1}{c}{ Agricultural } \\
\hline & & \\
& $+30 \%$ of water price & $25 \%$ of the vineyard is irrigated \\
\multirow{3}{*}{ Main assumptions } & $-10 \%$ due to savings & $(5 \%$ in 2008$)$ \\
& $+6.5 \%$ due to climate change; & $+100 \%$ of market gardening \\
& Constant household incomes & $-50 \%$ of orchards
\end{tabular}

Constant irrigation efficiency

Table 2 Main assumptions of the demand forecasting models and results at river-basin scale.

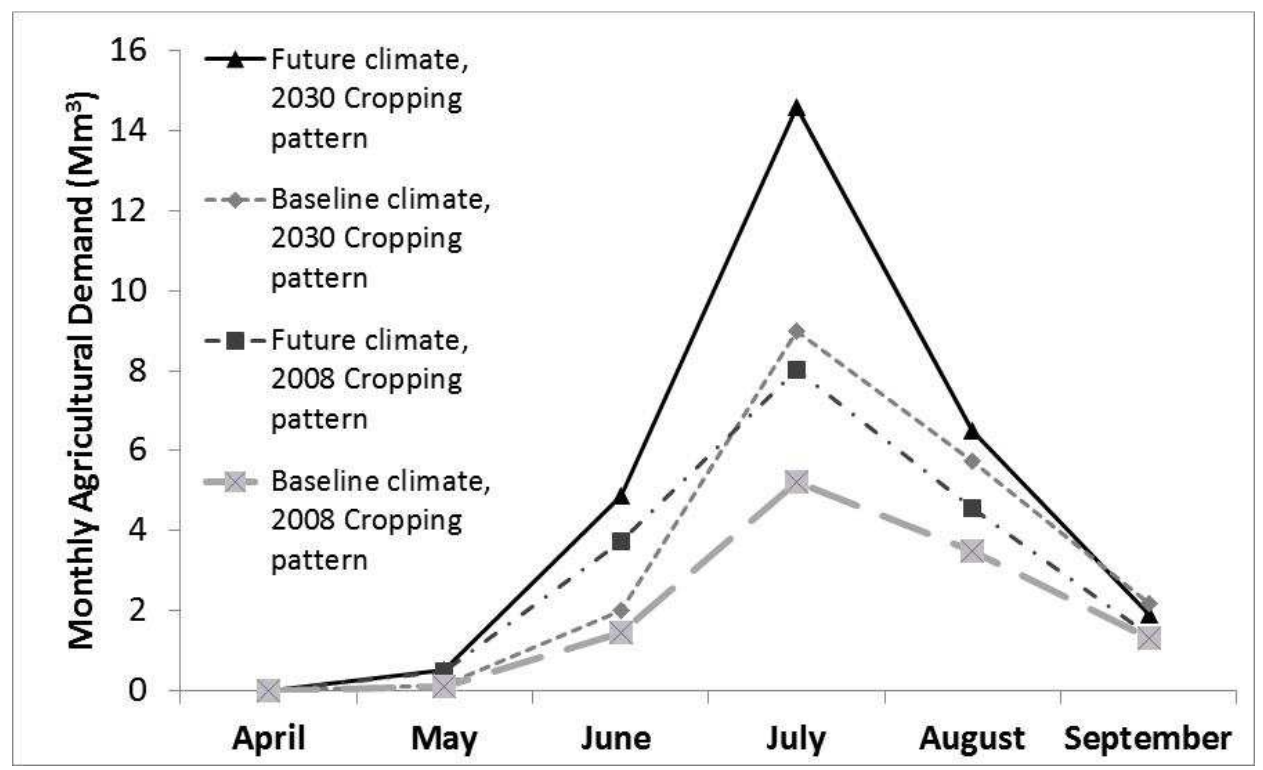

Figure 3: Changes in the agricultural water demand at basin scale for various scenarios.

\subsection{Future hydrological scenario}

For the chosen climate scenario, annual PET is likely to increase by $12 \%$ compared to the baseline period (1971-2000), with monthly variation from $+19.6 \mathrm{~mm}$ in June to $+1.9 \mathrm{~mm}$ in February. Regarding precipitation, the average decrease is expected to be $8 \%$ per year, characterized by an uneven distribution over the year ranging from $-50 \%$ in January to $+20 \%$ in August. The comparison of the 5-year monthly low flows (QMNA5) for the baseline and future periods illustrates the projected impact of the considered climate change scenario on water resources (simulated using tools described in section 2.3.3), leading to a $25 \%$ decrease in river flow at basin scale, though with spatial variation depending on the sub-basin (Table 3). 
Table 3: 5-year monthly low-flow (QMNA5) by sub-basin under baseline and future scenarios

\subsection{Adaptation measures}

Eleven types of water conservation measures were identified, nine of which target urban use (MU1 to MU9) and two of which relate to agricultural uses (MA1 and MA2). Urban water conservation measures are aimed at facilitating the adoption of water saving devices and practices, through subsidies or water conservation tariffs (MU5), and at reducing leakage in water distribution networks (MU1). The two agricultural water conservation measures consist of improvements in the technical efficiency of irrigation systems. MA1 relates to the modernization of traditional gravity irrigation system located in the upstream part of the river basin, replacing it with sprinkler irrigation. MA2 is aimed at developing drip irrigation in the lower part of the river basin, where water distribution already uses pressure networks. These measures are therefore mutually exclusive. Overall, 462 local adaptation measures were evaluated for the 84 UDUs, 19 measures for the 19 ADUs. Five groundwater projects and the desalination plants can supply 18 and 22 UDUs, respectively. The adaptation measures are characterized by their equivalent annualized cost and the saved and new water (Table 4), either by saving water on the demand side (water conservation) or by providing new resources on the supply side (capacity expansion). Measures are further detailed in Appendix A.

\begin{tabular}{cccc}
\hline Description of measure & $\begin{array}{c}\text { Maximum } \\
\text { annual volume } \\
\text { available in }\end{array}$ & $\begin{array}{c}\text { Average } \\
\text { annualized } \\
\text { unit cost }\end{array}$ & $\begin{array}{c}\text { UDU/ADU } \\
\text { affected } \\
\text { by the }\end{array}$ \\
\hline
\end{tabular}




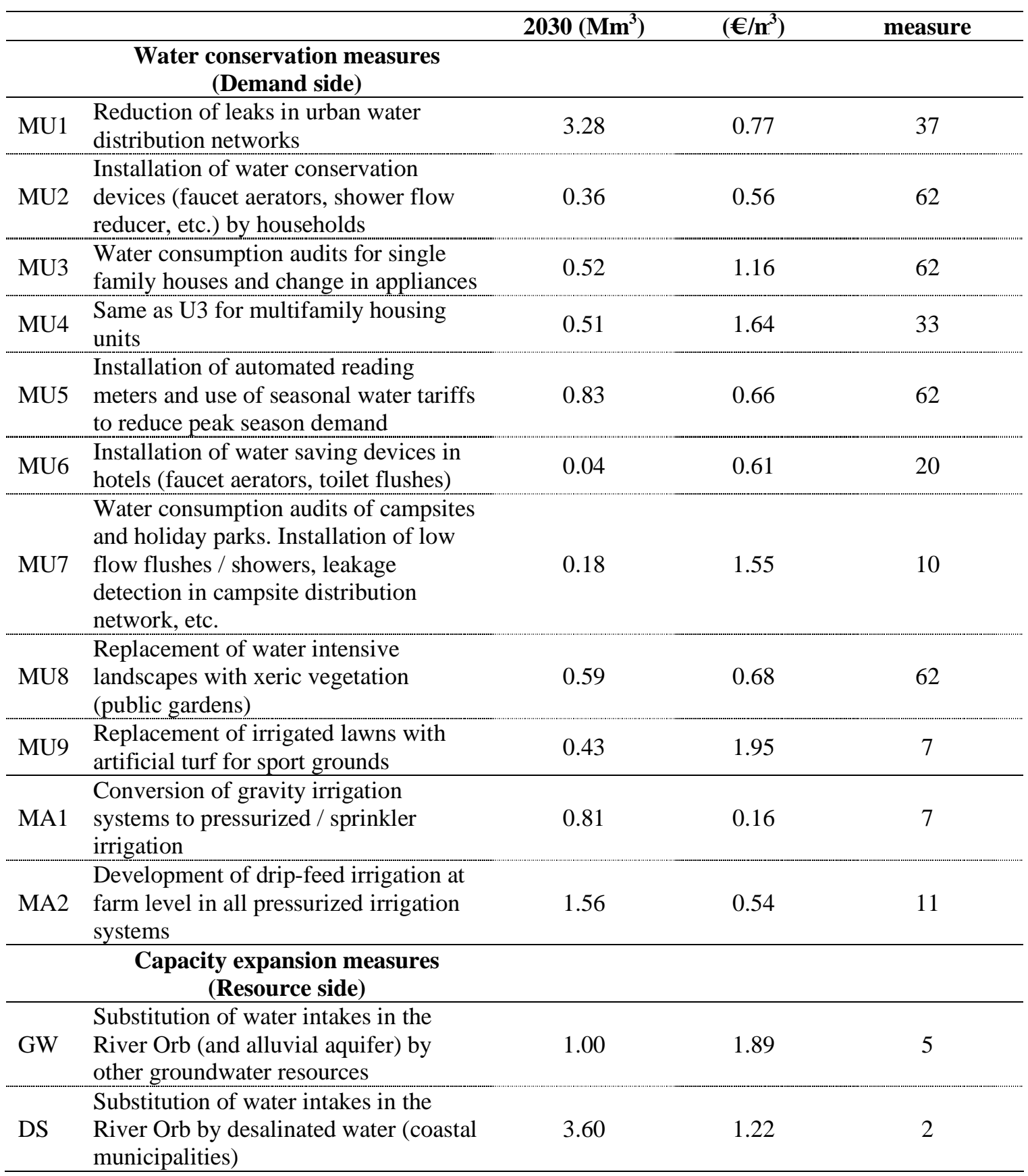

Table 4: Main characteristics of the adaptation measures

\section{Results}

\subsection{Present baseline scenario}

Using the optimisation model, Agricultural Deficit Indices (ADI, section 2.4.1) were computed for the historical hydrology and current demands (baseline scenario) and aggregated by sub-basin. Its spatial distribution was found to be uneven (Figure 4, top-right). In the baseline scenario, ADI reaches the 
maximum value (100\%) in the Mare (M4) and Jaur (J3) sub-basins, meaning that legal requirements are not fulfilled in these sub-basins (a deficit of magnitude equal to the demand occurs for a return period of less than 5 years). These sub basins correspond to tributaries of the River Orb that do not benefit from regulation by an upstream reservoir. This water deficit was mentioned in previous studies, and actions are already being implemented to address these issues (Vier and Aigoui, 2011). In contrast, the higher demand in the Orb sub-basins, which benefit from regulation from the upstream reservoir $(\mathrm{O} 2, \mathrm{O} 4, \mathrm{O} 5, \mathrm{O} 6, \mathrm{O} 10$ and $\mathrm{O} 12)$, can be supplied as required for the baseline scenario.

\subsection{Business-as-usual future scenario}

In the future business-as-usual (BAU) future scenario, the ADI increases under the impact of higher demands and scarcer water resources. In addition to the basins that show a deficit under the baseline scenario (M4 and J3), three more downstream sub-basins (O8, O10 and O12) show deficits for the future scenario (Figure 4, top-right). Thus, the decrease in summer flow impacts, first, the sub-basins that do not benefit from flow regulation from the reservoir; then, the downstream sub-basins with the highest demands (Figure 4, top-left) and the lowest natural flows (Table 3). The impact of global change thus challenges the current protection against dry summers provided by the reservoir and underlines the need for additional measures to meet environmental flow requirements and supply the agricultural demands in the future. 


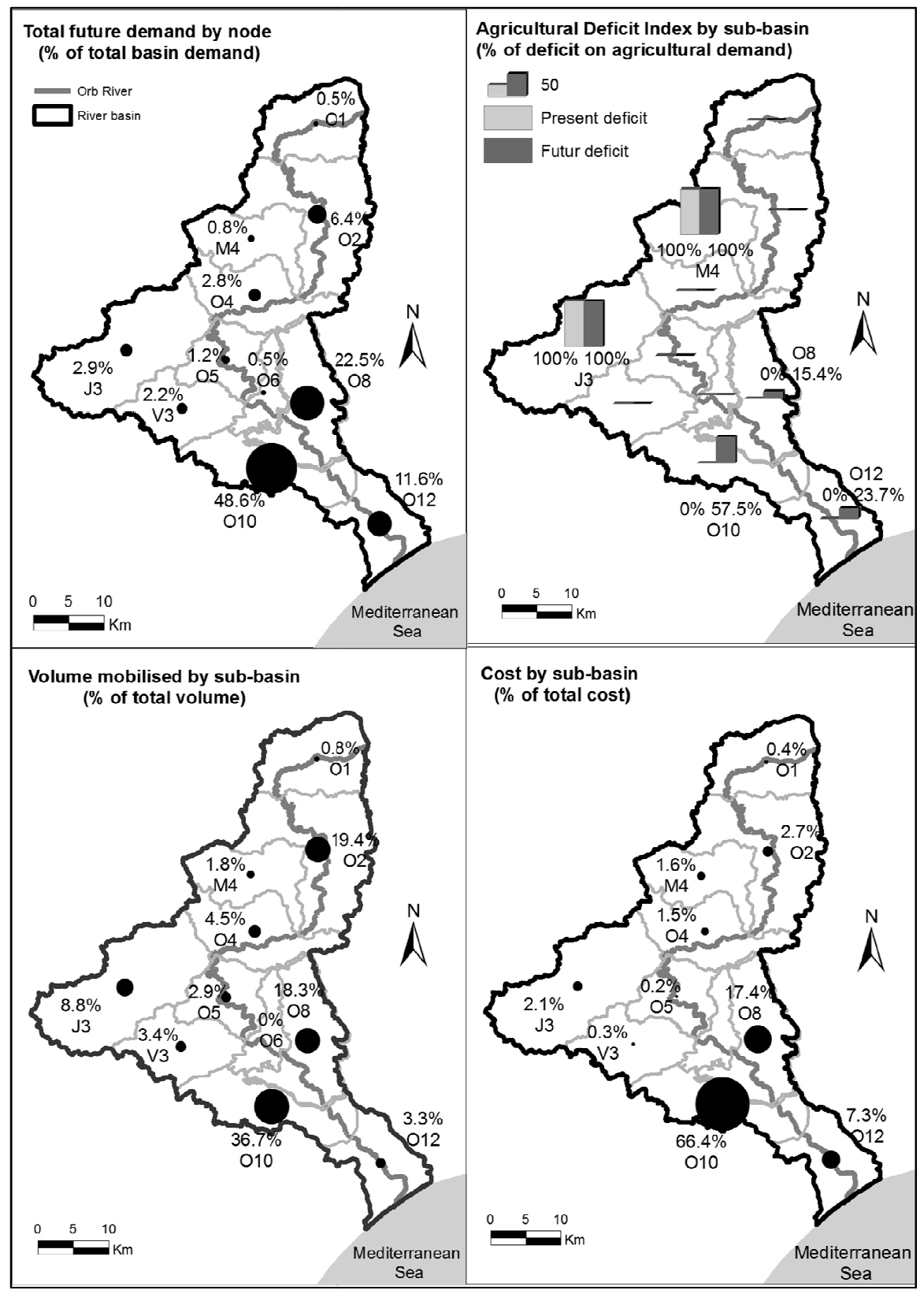

Figure 4 : Spatial distribution of: future demand in the Orb river basin (top-left); present and future agricultural deficit (top-right); saved and new (mobilised) water volume by sub-basins (bottom-left); and cost by sub-basin (bottom-right).

\subsection{Least-cost programme of adaptation measures}

A least-cost PoM was selected using the LCRBOM developed. At the sub-basin scale, the spatial distribution of the volumes to be mobilised (sum of the volumes saved by water conservation measures and provided by capacity expansion measures; Figure 4, bottom-left) and the associated costs (Figure 4, bottom-right) do not follow the pattern of the distribution of deficits (Figure 4, top- 
right). While the greatest deficits occur in tributaries M4 and J3 (ADI of $100 \%$ ), their contribution to the total cost and volume saved is low. This difference is explained by their lower demand, so there is less potential for water saving through efficiency improvements. The volumes and costs associated with these basins are lower even if the need exists. In contrast, the sub-basins with no deficit $(\mathrm{O} 1, \mathrm{O} 2$, O4, O5 and V3) have measures applied that also benefit other sub basins. The downstream basins with the highest demand take up the biggest share of the new and saved water volume. Sub-basin O12 has a high ADI, but few measures are applied in this area, given that it benefits from measures implemented further upstream.

\subsection{Trade-off analysis}

The least-cost optimisation model can also be used to assess potential trade-offs between agricultural demand, environmental requirements and economic cost of the PoM.

\subsubsection{Trade-off between agricultural demand and adaptation cost}

Increase in agricultural water demand is a key driver that can be actively influenced by local policy makers depending on the agricultural policy they promote (Table 1). Therefore, there is a possible trade-off between extending the area of irrigated agriculture (in particular irrigated vineyards) and the cost of water management measures that would be needed to offset the increased demand. To represent the effect of various agricultural development scenarios, we analysed the consequences of varying agricultural demand at basin scale by $+/-5$ and $10 \%$ (Figure 5 ). A $+/-10 \%$ variation in the agricultural demand at basin scale - representing a volume of $+/-2.9 \mathrm{Mm}^{3}$ per year -translates to a cost variation of between $-95 \%$ and $+137 \%$, (0.11 to $5.68 \mathrm{M} €)$, respectively). Consequently, the anticipated skyrocketing in the surface area of irrigated vineyard in the basin could challenge the management of water resources or represent an unaffordable cost.

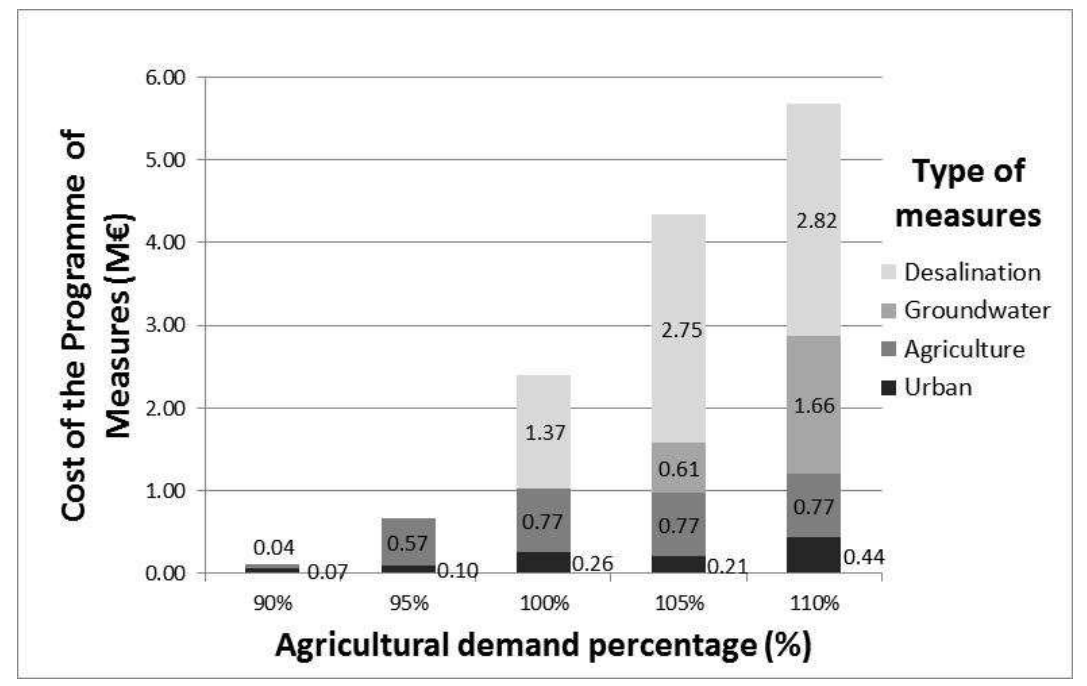

Figure 5: Cost of the PoM for different levels of agricultural demand at basin scale 
The defined least-cost PoM illustrates the great potential of demand management measures, as well as the fact that expensive capacity expansion projects (groundwater and/or desalination) could be avoided if the increase in agricultural demand were limited. For the lowest level of agricultural demand $(90 \%$ and $95 \%$ of the estimated future value) only demand management measures were selected. Measures to expand capacity are selected only once the increase in agricultural demand equals or exceeds $100 \%$ of the future scenario.

\subsubsection{Trade-off between environmental flow and adaptation cost}

The model can also be used to prioritise where it is economically more efficient to concentrate efforts in defining environmental flow requirements. Indeed, the total cost of the PoM can change significantly depending on the level on environmental flow imposed on each sub-basin (Figure 6). Variations of $+/-5 \%$ of the environmental flow requirements, applied in different sub-basins, give rise to contrasting impacts on the cost of the PoM. For a given variation of in-stream flow requirements, the impact on PoM cost is highest in O1. While sub-basins $\mathrm{O} 2$ and $\mathrm{O} 4$ present greater environmental flow requirements than $\mathrm{O} 1$, the cost of the PoM at basin scale is less sensitive to their environmental flow requirements. These results highlight the strategic importance of ecological flow definition in sub-basin O1, which accommodates the Monts d'Orb reservoir that regulates most of the River Orb flow. Most in-stream flow in this part of the river comes from reservoir releases. Therefore, decision makers control the flow regime in this section of the River Orb, which allows them to further assess the trade-off between costs and environmental requirements.

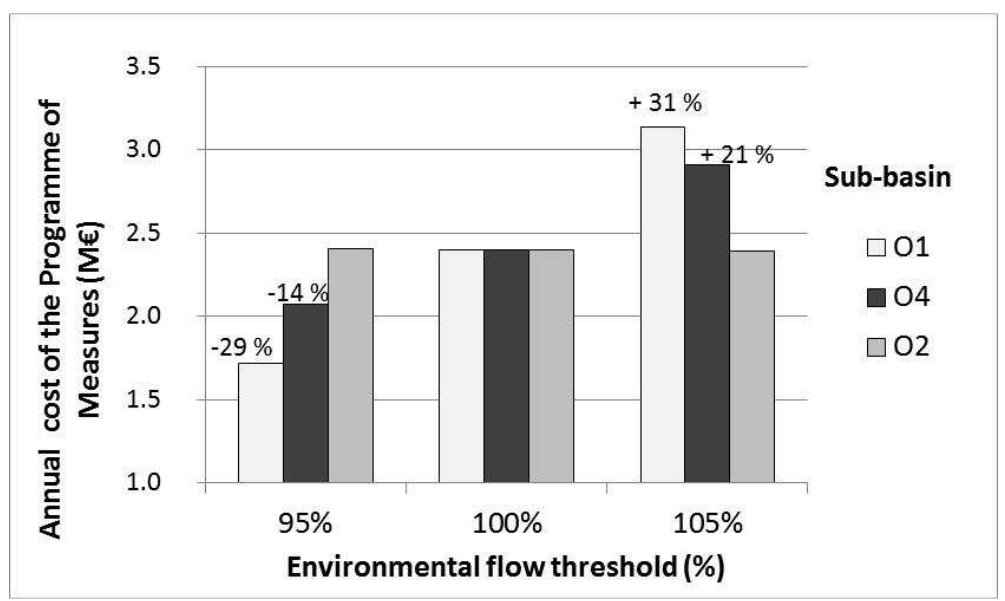

Figure 6 : Cost of the PoM for different environmental flow thresholds in three sub-basins (O1, 02 and 04) 


\subsubsection{Trade-off between environmental flow requirement, adaptation cost and agricultural demand}

A fixed variation in volume (ranging from -0.1 and $+0.1 \mathrm{Mm}^{3} / \mathrm{month}$ ) was applied to both the environmental flow in the headwaters of the basin (sub-basin O1) and to the agricultural demand of the downstream ADU, "A14" (Figure 7). In this case, the total cost of the PoM exhibits higher sensitivity to variations in agricultural demand in ADU "A14" than to environmental flows in sub basin "O1". The same increase in PoM cost allows an increase of agricultural demand in ADU "A14" (grey arrow) by $0.1 \mathrm{Mm}^{3} /$ month or an increase of environmental flow in sub-basin O1 by 0.2 $\mathrm{Mm}^{3} /$ month (dark arrow). This comparison illustrates the kind of trade-off that can be compared at river basin scale.

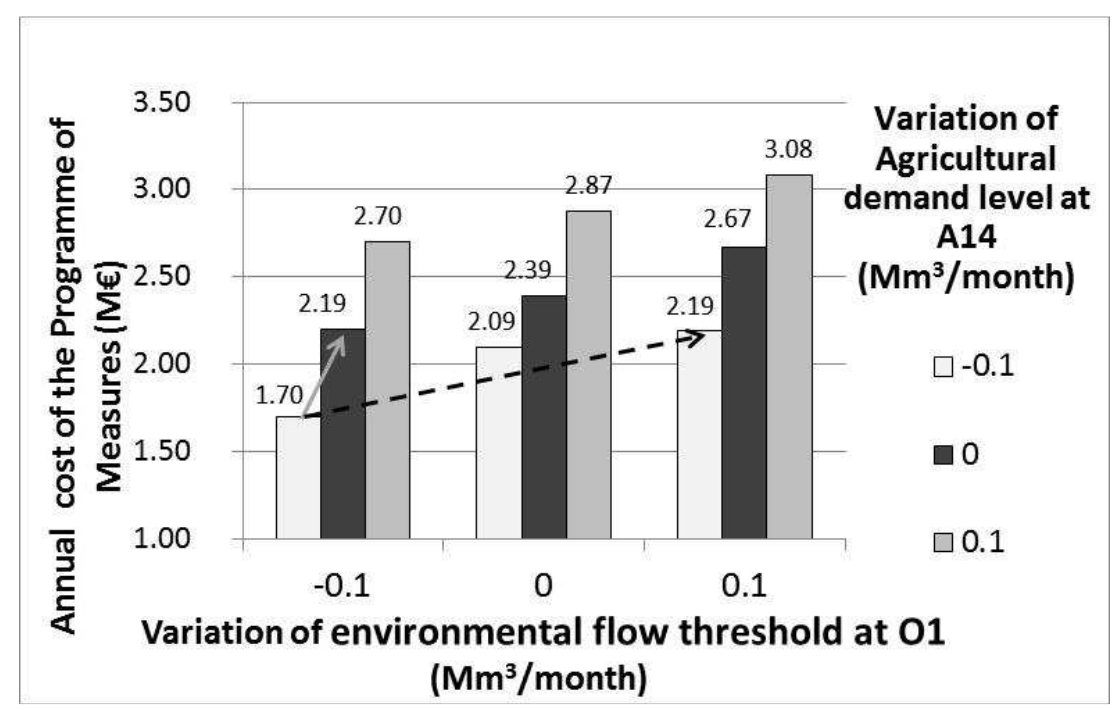

Figure 7 : Cost of the Programme of Measures for different levels of agricultural demand in A14 and environmental flow in 01

\section{Discussion}

\subsection{Framework limitations}

The modelling framework presented provides a useful method to explore future adaptation strategies in the face of global change. However, the method implemented in the present study has revealed several caveats and limitations that need to be acknowledged.

The first limitation is the lack of any assessment of uncertainty. Uncertainty in water resources modelling stems from an incomplete understanding of the hydrological processes modelled (e.g. surface-groundwater interactions), from imprecise hydrological data used for calibration, and from the choice of models used for simulating sub-components of the system (water demand, hydrological 
processes), (Refsgaard et al., 2007). In the case of the analysis of global change scenarios in which we no longer assume that the hydrology is stationary, this is far more complex, since we need to add the uncertainty on the meteorological variables (defined as plausible scenarios derived from GCM projections, with a large range of variations among them) and on the resulting inflow time series that define available resources in the basin (Brown and Wilby, 2012). Moreover, land use changes will affect water demand but also affect the hydrology and even the climate, creating a circle of feedbacks demanding different approaches for designing adaptation under uncertainty (eg. Brown et al. 2012). Large ensembles combining several climate models and emission scenarios could be needed to quantify the uncertainty linked to climate modelling (Barsugli et al., 2012). However, it is still a matter for discussion whether the improvement achieved by using ensembles instead of a single model is as large as expected, and how this translates into improvements in the projections (Knutti et al., 2010). Other sources of uncertainty are inherent to each discipline involved in the framework as for instance water demand forecasting that relies on future socio-economic conditions (e.g. agricultural markets) with hardly predictable uncertainties. Overall, given the resulting global uncertainty, there is call for a new approach to adaptation strategies. The top-down approach - which underlies the modelling framework presented in this paper - could be complemented by a bottom-up approach, which analyses how a set of possible strategies perform over a large range of possible futures (Wilby and Dessai, 2010; Lempert and Groves, 2010). To illustrate the development of the framework, we indeed have used one single climate and demand scenario, but the same approach could be developed under different climate and demand scenarios, and then proceed with a characterization of the robustness of the proposed adaptation plan across these scenarios.

Another limitation of our modelling framework lies in its normative nature. Indeed, it identifies a solution that can theoretically maximise social welfare but it does not integrate other factors considered by stakeholders to select relevant adaptation strategies. A condition for implementing the optimised solution is the existence of a strong planning authority and a central decision-making capability to implement the optimal solution or an alternative approach that could lead to a close-tooptimal solution. This issue is called the limitation of 'perfect cooperation' (Madani, 2010), or alternatively, 'perfect command and control' that is assumed by the optimisation procedure. Actually, no such authority exists in the context of river basin management in France (or in many other countries). Relevant stakeholders (urban, agricultural, and environmental) are represented in the basin authority and sit around the table to negotiate a programme of measures. As such, the model can provide useful insight for water planners acting at policy level (such as a water agency, government agency or county council), who have been associated with the development of this initial model. However, the model would not provide the range of information needed by local stakeholders (water users' representatives, elected politicians at municipal levels) who will be concerned by the actual implementation of some of the adaptation measures considered in our study. 
In future research, we intend to explore, in conjunction with more qualitative research (focus groups, scenario workshops, participatory modelling) how the model could be used as a medium for wider stakeholder participation in adaptation planning. This will imply not only a discussion of the model assumptions and structure but also a possible restructuring of the model to include additional processes and output indicators as required by stakeholders. This also implies an opportunity to incorporate lay stakeholders' knowledge into the modelling framework - moving from an interdisciplinary to a transdisciplinary approach (Pohl, 2005).

For instance, the distribution of costs associated with the optimal solution (or 'first-best' solution to use economists' terminology) may not be considered fair and equitable; there may be calls to search for a negotiated 'second-best' option - involving financial transfers between stakeholders. Issues such as agreements on costs and measures allocation among the different players in a basin could be further integrated in the analysis. This is one of the challenges to be addressed next in our modelling research. Other limitations are inherent to the optimisation procedure selected, as it is the 'perfect foresight' of deterministic optimisation (Labadie, 2004). By using this kind of optimization, we assume that an allknowing manager would know the hydrological future with certainty and therefore will be able to select ideally the measures or to release water from the reservoir when needed. This leads us clearly to an overoptimistic result, this means an underestimation of the adaptation needed, and therefore the results given here must be taken as the lower bound of the adaptation strategy needed. This optimization method, even if appropriate to the relative simplicity of the case study, could need to be adapted to more complex water resource systems (greater storage capacity and temporal correlation of the hydrology) as the importance of perfect foresight generally decreases significantly with the amount of over-year storage (Draper et al., 2011). However, the effects of perfect foresight have been considered as acceptable even in some complex water systems (ie. California water supply network, Newlin et al., 2002 and Pulido-Velazquez et al., 2004). This part of the framework presented could require further improvement to overcome the perfect foresight of the optimization looking at methods such a Stochastic Dynamic Programming (SDP) or combining simulation models with genetic algorithms.

Finally, other types of measures (water quality measures, river restoration measures, etc.) would also need to be included in a general adaptation programme of measures, although here the focus is on water quantity issues (water scarcity). Assessing the trade-offs at stake between the planning objectives of environmental preservation, economic development and adaptation cost, is a necessary step for the definition of a programme of measures. The next step would be as well to consider the phasing of the investment needed to achieve the objectives defined following a more conventional least-cost planning approach to advise on the investment required or a real option analysis (Jeuland and Whittington, 2014) to include as well the possibility to learn along the planning process. The framework is indeed a first step, in terms of adaptation, towards what could be the development of a full adaptive management strategy that would consider an iterative process of planning, implementing 
and updating the plan as more information is obtained and lessons are learned by the decisions makers when they experience changing conditions.

\subsection{Insights from the interdisciplinary approach}

This paper illustrates how analysing long-term changes and adaptation to global change in river basin management requires bringing multiple scientific disciplines together and binding them into a single framework, facilitated by integrated modelling. Our experience suggests that deploying such an interdisciplinary approach is by no means a trivial task. During our research, a continuous (and timeconsuming) dialogue took place to construct a shared representation of the river basin, specify the optimisation problem, identify and formalize water management constraints in that model, choose spatial and temporal scales at which the model should be developed and the nature of adaptation measures to be considered. A conceptual model was developed gradually and, through an iterative process, progressively refined. Finding an appropriate temporal and spatial resolution of water resources modelling, which would be consistent with the economic analysis of water demand forecast, was also an iterative process. Each researcher had to adapt their approach (concept and tools) to fit in the overall optimisation model, seen as an end-point for research and integration. The modeller played a role of 'guardian of integration', as already reported in the literature (Kragt, et al. 2013). This integrative approach stands in contrast with multidisciplinary research where the various disciplines basically do their own thing in parallel, their conceptual and methodological choices remaining independent from each other (Mollinga, 2009). Creating this dialogue implies that researchers be willing to cross-disciplinary boundaries, that they invest time and energy to appropriate concepts and methodologies of the other disciplines. The success of such interdisciplinary approaches requires an attitude of 'engaged problem solvers' rather than 'detached specialist' (Pohl, 2005). This clearly rises team-work challenges (how to ensure communication, engagement, trust, coordination of disciplines) and also challenges the way the academia sometimes evaluates such integrative interdisciplinary research (Kragt, et al. 2013), these challenges being part of a cultural and historical barrier to the integration across disciplines (Hamilton, et al. 2015).

\section{Conclusions}

In Europe, as in many other parts of the world, recent legislation increasingly compels water planners to conduct ex-ante integrated assessment of policies deployed to adapt to global change. Because of the wide range of social, agricultural, environmental, economic and hydrological impacts associated with global change, policy analysts need to deploy interdisciplinary evaluation methodologies. This paper suggest that least-cost river basin optimisation models can provide a useful framework for 
integrating knowledge from various scientific disciplines, including economics, agricultural, hydrological and engineering sciences, to design global change adaptation strategies at basin scale.

From a policy perspective, least-cost river basin optimisation models inform policy makers' decisions at the regional or basin level, by providing three main types of results. First, they can help to prioritise the allocation of measures in the basin to satisfy all constraints at a minimum total cost. The model helps users to understand that the optimal programme of measures is characterized by a spatial distribution of costs and water volume (saved or created), which is proportional neither to the deficit nor to the demands. This fact reflects differences in the actual efficiency of the measures at basin scale, depending on their spatial location. A water conservation measure implemented upstream not only allows the environmental target in the sub-basin to be met but also contributes to solving the problem in all downstream sub-basins. The integrated model captures this issue by accounting for the upstream-downstream interactions in the basin. These results provide valuable insight into the definition of first-best solution that could be a basis for negotiating a basin-scale adaptation strategy with the relevant stakeholders.

Second, the model helps to prioritise the type of actions that need to be implemented. For instance, results of our case study suggest that certain water conservation measures should be systematically implemented, even for the lowest level of water deficit. The cost minimisation approach leads to a recommendation to implement water conservation measures in agriculture before engaging in projects to increase capacity. However, if agricultural demand grows above a certain value, capacity expansion measures - such as groundwater development or desalination plants - are needed to ensure that urban water demand and environmental flow targets are fully met. Further analysis could be conducted to assess the threshold level of agricultural development that would make capacity expansion measures unavoidable, and provide elements to further match water resources management and agricultural development at planning level.

Third, the model can help evaluate possible trade-offs between development of uses, environmental objectives and costs of water management. This is useful information for regional and river basin level policy makers as they attempt to reconcile agricultural and urban development policies with environmental objectives. The model can be used to identify boundaries (in the mathematical sense of the word) between agricultural development, urban growth, water management cost and environmental objectives.

The interdisciplinary modelling framework presented takes a step toward better integration of disciplines within a coherent framework for the integrated assessment of water resource systems' performances. It allows fruitful insights into water management that exceed the sum of particular disciplinary contributions. Even if the increasing complexity of water management issues call for the adoption of such an approach, whether this type of tools will become part of water managers' toolbox remains an open debate. It does not only raise questions about the financial resources to be dedicated 
to the development of such tools, but also about its acceptability and appropriation by those policy makers, technicians and stakeholders who are often not so familiar with integrated interdisciplinary approaches.

\section{Acknowledgements}

The study has been partially supported by ONEMA, by the Scarce Project (Consolider-Ingenio 2010 CSD2009-00065) and IMPADAPT project (CGL2013-48424-C2-1-R) of the Spanish ministry MINECO (Ministerio de Economía y Competitividad) with European FEDER funds. Corentin Girard is supported by a grant from the University Lecturer Training Program (FPU12/03803) of the Ministry of Education, Culture and Sports of Spain. We also acknowledge the CERFACS for the climate scenarios provided from their SCRATCH 2010 dataset (March 2012 release -

http://www.cerfacs.fr/ page/work/scratch/). We are very grateful to S. Chazot (BRLi), E. Vier and F. Aigoui (GINGERGROUP) and L. Rippert and its team from the SMVOL for their advice during the research and for the data provided. We thank as well the anonymous reviewers, and the Editor-inChief of Environmental Modelling and Software, Anthony Jakeman, for their support in the improvement of the manuscript and their encouraging comments. 
Appendix A:

MU1 leakage reduction campaign in the water supply distribution network: This measure consists of a diagnosis of the network to identify leakages; then the leaking pipes are repaired. The water saved is estimated as the difference between the volume of losses before and after the repair. The life span of this measure is estimated to be 15 years.

MU2 Water saving kits for households: Water saving kits are provided to households on a voluntary basis. A $25 \%$ participation rate is assumed for households to collect their kits from the municipality (free of charge), of which only $75 \%$ are finally installed. The kit includes water saving devices for showers, sinks and toilets, according to the type of house (single or multi-family unit).

MU3 Water saving audit for individual houses: A specialist is paid to audit individual houses with or without a garden. A diagnosis of leakages is carried out and water saving devices are installed. Low cost devices are installed by default and the specialist is assumed to be paid for 2 hours of work as a plumber (40€/hour). The household pays the costs up to the threshold of savings realized on the water and electricity bill, the public authority adding a subsidy to pay the remainder. The rate of uptake is assumed to be $50 \%$, thanks to the positive impact of the subsidy.

MU4 Water saving audit for collective housing: This measure is applied only in municipalities with more than a hundred collective housing units (flats managed together). Managers of this type of housing are always looking for ways to cut costs, therefore they are assumed to adopt this measure readily $(75 \%)$ and the subsidies can be less than in M3. The measure offers the support of a professional to locate and fix leakages and to install water saving devices. Installation of individual water meters is also promoted and subsidized.

MU5 Seasonal pricing policy: The price of water is increased by $50 \%$ during the peak period (from the $15^{\text {th }}$ of May to the $15^{\text {th }}$ of September). The price is decreased at other times of year in order to maintain an equivalent water bill for the permanent inhabitants. Only certain costs associated with the implementation of this measure are paid by the public authority, namely: remote reading water meters are installed and cost $5 €$ per year per household more than classic meters. The meter must also be read automatically once during the first few days of the peak period ( $3 €$ per household).

MU6 Water saving kits in hotels: Hotels receive subsidies of $20 \%$ of the cost of water saving devices in their rooms. A distinction is made between hotels with two stars or less, and luxury hotels of three stars or more, according to the quality of the water saving devices installed. The uptake rate is assumed to be high ( $75 \%$ ) due to the benefit generated by water savings.

MU7 Water audit in campsites: On a voluntary basis, a campsite can apply for a free water audit to reduce their leakages. The cost of such audit is fixed at $450 €$, the campsite owner pays the cost of fixing the leakage. It is assumed that $50 \%$ of campsites will volunteer, of which $60 \%$ will reduce their leakages. The savings are estimated to be $25 \%$ of the initial consumption.

MU8 Conversion to Mediterranean vegetation: 
Planting in public parks is modified to introduce vegetation adapted to drought. A design requiring less watering and more mineral cover or trees is developed allowing the soil to be protected against evaporation. Only the additional costs (compared to the classic design) are considered and these are estimated to be $8.30 € / \mathrm{m}^{2}$. The savings are $50 \%$ over the first three year and $100 \%$ afterwards. Only $10 \%$ of the public parks apply this measure.

MU9 Replacement of irrigated lawns with artificial turf for sport grounds

The existing football and rugby pitches are converted to artificial synthetic grass at a cost of $230000 €$ per field. Only $20 \%$ of the investment cost is subsidized by the public authority and $75 \%$ of the fields are converted. The life span of the field is 10 years.

MA1 Modernising gravity irrigation: The measure corresponds to the modernization of gravityirrigated systems located upstream in the river basin. The management of the irrigation channel is improved, and pumping stations are built along the channel to irrigate areas of 150 to 300 ha. This is linked to conversion to sprinkler irrigation. For the distribution system, the investment costs are assumed to be $6500 €$ per hectare, with a life span of 40 years. Maintenance costs are assumed to be 1 $\%$ per year and the energy cost, $30 € /$ ha.

MA2 Efficiency improvement in pressurized irrigation: The second measure is the development of drip-feed irrigation in the downstream part of the river basin, where piped distribution networks are already installed (therefore, a zero cost is associated with the distribution network). The investment cost is defined as $2000 € /$ ha for a life span of 10 years, linked to operation and maintenance cost of $78 € /$ ha. The efficiency associated with the drip-feed irrigation remains at 0.9 . The annualized cost of this measure is $325 € / \mathrm{ha}$. 
Appendix B: Optimisation models: objective functions and constraint equations

\section{B.1. Water resources optimisation model:}

Objective function:

(Eq. B. 1) Minimize $\prod_{D}=\sum_{t} \sum_{a} D e f_{a, t}^{T^{*}}$

Where, $\mathrm{t}$ is the time step index (monthly); "a" is the index of the ADU, and $D e f_{a, t}^{T^{*}}$ is the deficit for $\mathrm{ADU}$ a at month $\mathrm{t}$ with a return period $\mathrm{T}^{*}$ lower than $\mathrm{T}$.

\section{Subject to:}

B.2.1. Supply of demand:

(Eq. B. 2) $\quad S U_{u, t}=D U_{u, t} \forall u, t$

(Eq. B. 3) $\quad S A_{a, t}=D A_{a, t}-D e f_{a, t}^{T}-D e f_{a, t}^{T^{*}} \forall a, t$

Where SU and SA are the volume of water supplied at each time step to $\mathrm{u}$ and a respectively; DU and DA are the demand of the ADU " $\mathrm{u}$ " and ADA "a" at t respectively;Def $f_{a, t}^{T}$ is the variable allowing a 5year deficit; $D e f_{a, t}^{T^{*}}$ is the variable accounting for the extra deficit over the allowed 5-year deficit one.

\section{B.2.2. Deficit frequency constraint:}

(Eq. B. 4) If $D e f_{a, t}^{T} \geq 0$ then $\mathrm{DC}_{\mathrm{yr}}=1$ else $\mathrm{DC}_{\mathrm{yr}}=0$

(Eq. B. 5) $\quad \sum_{y r} D C_{y r} / N \leq 1 / T$

Where DC is the annual deficit indicator of the year $\mathrm{yr} ; \mathrm{N}$ is the total number of years, and $\mathrm{T}$ is the return period fixed by the legislation for an acceptable deficit.

\section{B.2.3. Supply and resources balance:}

(Eq. B. 6) $\quad \mathrm{V}_{t, n}=\mathrm{V}_{t-1, n}+\mathrm{I}_{t, n}+\mathrm{D}_{t, n}-\mathrm{SU}_{t, n}-\mathrm{SA}_{t, n}+\mathrm{R}_{t, n}-\mathrm{E}_{t, n} \forall \mathrm{t}, \mathrm{n}$

Where $\mathrm{n}$ is the number of indices of the node; $\mathrm{I}$ is the monthly inflow at node $\mathrm{n}$; $\mathrm{D}$ is the discharge from $\mathrm{n}$; Vis the volume of the reservoir; $\mathrm{R}$ is the volume released from the reservoir (only reservoir at $\mathrm{n} 1$ else $\mathrm{V}=0$ and $\mathrm{R}=0$, at $\mathrm{t}=0$ with set $\mathrm{V}=\mathrm{V}_{0}=19.7 \mathrm{Mm}^{3}$ ).

\section{B.2.4. Environmental flow constraints:}

(Eq. B. 7) $\quad \mathrm{D}_{t, n} \geq \mathrm{E}_{t, n} \quad \forall \mathrm{t}, \mathrm{n}$

Where $\mathrm{E}$ is the level of the in-stream environmental flow requirements at $\mathrm{n}$.

\section{B.2.5. Reservoir constraint:}


(Eq. B. 8) $\quad \operatorname{Vmax}_{t} \geq \mathrm{V}_{t, n 1} \geq \operatorname{Vmin} \forall \mathrm{t}$

Where Vmin and Vmax are the minimum and maximum volume of the reservoir at $\mathrm{n} 1$.

B.2.6. Return:

(Eq. B. 9) $\quad \mathrm{R}_{n, t}=\sum_{\mathrm{u}} \mathrm{SU}_{u, t} \times \mathrm{MC}_{-} \mathrm{RU}_{u, n}+\sum_{\mathrm{a}} \mathrm{SA}_{a, t} \times \mathrm{MC}_{-} \mathrm{RA}_{a, n} \quad \forall \mathrm{t}, \mathrm{n}$

Where MC_RU is the connectivity matrix connecting the return from a supply SU of an UDU to a node $\mathrm{n}$ (respectively ADU).

B.2.7. Evaporation from the reservoir

(Eq. B. 10) $\quad A_{t, n}=a \times V_{t, n}+b \quad \forall t, n$

(Eq. B. 11) $\quad \mathrm{EV}_{\mathrm{t}, \mathrm{n}}=\frac{\mathrm{A}_{\mathrm{t}, \mathrm{n}}+\mathrm{A}_{\mathrm{t}-1, \mathrm{n}}}{2} \times \frac{\mathrm{ER}_{\mathrm{t}, \mathrm{n}}}{1000} \quad \forall \mathrm{t}, \mathrm{n}$

Where $\mathrm{a}$ and $\mathrm{b}$ are two parameters defined by linear regression; $\mathrm{A}$ is a positive variable presenting the area of the reservoir (in $\mathrm{km}^{2}$ ) calculated from the Volume $\mathrm{V}$ of the reservoir; ER is the monthly Evaporation Rate defined in $\mathrm{mm}$ and therefore divided by 1000 to calculate the evaporation in $\mathrm{Mm}^{3}$ directly.

\section{B.2. Least-cost river basin optimisation model:}

The precedent equation are either maintained or modified as indicated below.

\section{Objective function:}

(Eq. B. 12) Minimise $\prod=\prod_{C}+M \times \prod_{D}$

Where: $\prod_{D}$ is defined in Eq B. 1; M is a very large positive number, higher than the sum of the cost of all the other measures;

(Eq. B. 13) $\quad \prod_{\mathrm{C}}=\sum_{\mathrm{m}} \mathrm{A}_{m} \times \mathrm{C}_{m}+\sum_{\mathrm{t}} \sum_{\mathrm{m}} \mathrm{V}_{m, t} \times \mathrm{VC}_{m, t} / \mathrm{N}$

Where, $\mathrm{m}$ is the index of the measures; $\mathrm{A}$ the activation binary variable; $\mathrm{C}$ the equivalent annual fixed cost of the measure; $\mathrm{V}$ the volume of water coming from the measures (only for ground water and desalination projects); VC the variable cost of the measures proportional to the volume. (The equation below presents a detailed version of this equation)

(Eq. B. 14) $\Pi_{\mathrm{C}}=\sum_{\mathrm{ma}} \mathrm{AA}_{m a} \times \mathrm{CA}_{m a}+\sum_{\mathrm{mu}} \mathrm{AU}_{m u} \times \mathrm{CU}_{m u}+\sum_{\mathrm{mgw}} \mathrm{AGW}_{g w} \times \mathrm{CGW}_{g w}+$ $\sum_{\mathrm{mds}} \mathrm{ADS}_{m d s} \times \mathrm{CDS}_{m d s}+\sum_{\mathrm{t}} \sum_{\mathrm{mgw}} \mathrm{VGW}_{g w, t} \times \mathrm{VCGW}_{g w}+\sum_{\mathrm{t}} \sum_{\mathrm{mds}} \mathrm{VDS}_{m d s, t} \times$ VCDS $m d s$

Where, mu, ma, mgw and mds are indices of the measures of urban or agricultural demand, groundwater or desalination project respectively; $t$ is time step (monthly) index; AA, AU, AGW, ADS 
are binary activation variables of the measures mu, ma, mgw and mds; CU, CA, CGW, CDS are fixed equivalent annual cost $(€)$ of mu, ma, gw, mds respectively; VGW and VDS are the volume of water in $\mathrm{Mm}^{3} /$ month of the measure mgw and mds respectively; VCGW and VCDS are the variable costs of the measures gw and mds in $€ / \mathrm{Mm} 3 /$ month divided by the total number of year $\mathrm{N}$ of the optimisation.

\section{Subject to:}

B.2.1. $\quad$ Demand and supply side measures

(Eq. B. 15)

$$
\begin{aligned}
\mathrm{SU}_{t, u} & =\mathrm{DU}_{t, u}-\sum_{\mathrm{mu}} \mathrm{AU}_{m u} \times \mathrm{VU}_{m u, t} \times \mathrm{CM}_{-} \mathrm{U}_{-} \mathrm{MU}_{m u, u} \\
& -\sum_{\mathrm{mgw}} \mathrm{VGW}_{g w, t} \times \mathrm{CM}_{-} \mathrm{GW}_{-} \mathrm{U}_{m g w, u}-\sum_{\mathrm{mds}} \mathrm{VDS}_{m d s, t} \times \mathrm{CM}_{-} \mathrm{DS}_{-} \mathrm{U}_{m d s, u} \quad \forall \mathrm{t}, \mathrm{u}
\end{aligned}
$$

$$
\mathrm{SA}_{t, a}=\mathrm{DA}_{t, a}-\sum_{\mathrm{ma}} \mathrm{AA}_{m a} \times \mathrm{VA}_{m a, t} \times \mathrm{CM}_{\mathrm{A}_{\mathrm{MA} \mathrm{ma}, \mathrm{a}}}-D e f_{a, t}^{T}-D e f_{a, t}^{T^{*}} \forall \mathrm{t}, \mathrm{a}
$$

Where SU and SA are the supply of $\mathrm{u}$ (a respectively) after the activation of the measures; VU and VA are water saving $\left(\mathrm{Mm}^{3} /\right.$ month) for mu or ma respectively; CM_U_MU is a Connectivity Matrix between the "mu" and the demand "u" (Respectively CM_A_MA); CM_GW_U: Connectivity Matrix between the measures "mgw" and the demand "u", Respectively CM_DS_U.

\section{B.2.2. Desalination measures:}

Capacity and activation constraint: limits the capacity of the desalination plant and the availability of water to connectable UDUs.

(Eq. B. 17) $\quad \sum_{\mathrm{u}} \mathrm{VDS}_{m d s, t} \times \mathrm{CM}_{-} \mathrm{DS} \_\mathrm{U}_{m d s, u} \leq \mathrm{ADS}_{m d s} \times \mathrm{CapDS}_{m d s} \quad \forall \mathrm{t}$, mds

Where CapDS is the maximum capacity of a desalination plant mds.

\section{B.2.3. Groundwater measures:}

Capacity and activation constraint: limits the capacity of the groundwater project and the availability of water to connectable UDUs.

(Eq. B. 18) $\quad \sum_{\text {mgw }} V_{G W} W_{m w, t} \times$ CM_MGW_GW $\leq \mathrm{AGW}_{g w} \times \mathrm{CapGW}_{g w} \forall \mathrm{t}, \mathrm{gw}$

Where CapGW is the maximum capacity of a groundwater project gw.

\section{B.2.4. Exclusivity constraint: ensures the mutual exclusivity of groundwater projects}

(Eq. B. 19) $\quad \sum_{\mathrm{gw}_{w}} \mathrm{AGW}_{g w} \times \mathrm{MC}_{-}$Excl_GW_GW $\leq 1$ 
Where MC_Excl_GW_GW is a matrix ensuring the mutual exclusivity of groundwater projects. 
Appendix C: Result of the calibration and validation of the hydrological model on the 11 sub-river basins of the Orb river basin.

The results of the validation and calibration of the hydrological model indicate variable calibration and validation quality (Table A and Figure A) that were considered good enough overall to be able to use the model for climate change impact studies. On the one hand, the difference between simulation and observation is due in part to some inconsistency of the natural flow restoration. Water demands to meet urban and agricultural supply are considered accurate enough at the monthly time-step to be added to observed river discharges. On the other hand, the difference could be also partially due to surface water seepages that recharge the calcareous aquifers further downstream in the basin. Indeed, the statistics indicating the poorest performance in Table A are obtained for the sub-basins, where these surface-groundwater interactions are probably the cause of the significantly lower specific river discharges $(\mathrm{O} 5, \mathrm{O} 8, \mathrm{O} 10$ and $\mathrm{O} 12)$. This is linked to the coarse description of the surface-groundwater interactions due to the lack of relevant data in such a complicated geological context. Applying models able to simulate groundwater dynamics or stream-aquifer interactions should improve the quality of the modelling. However, this raises the need to acquire new data particularly in order to quantify the part of the river flow that disappears underground in the sink holes specific to limestone regions.

Finally, the validated models for each of the sub-basins were used to simulate the natural river discharge at their respective outlets, using the historical climate data for the baseline period (19712000) and inputs from the downscaled ARPEGE climate scenario for the future period (2046-2065). The obtained discharge time series were then integrated in the water management model constructed at river basin scale. 

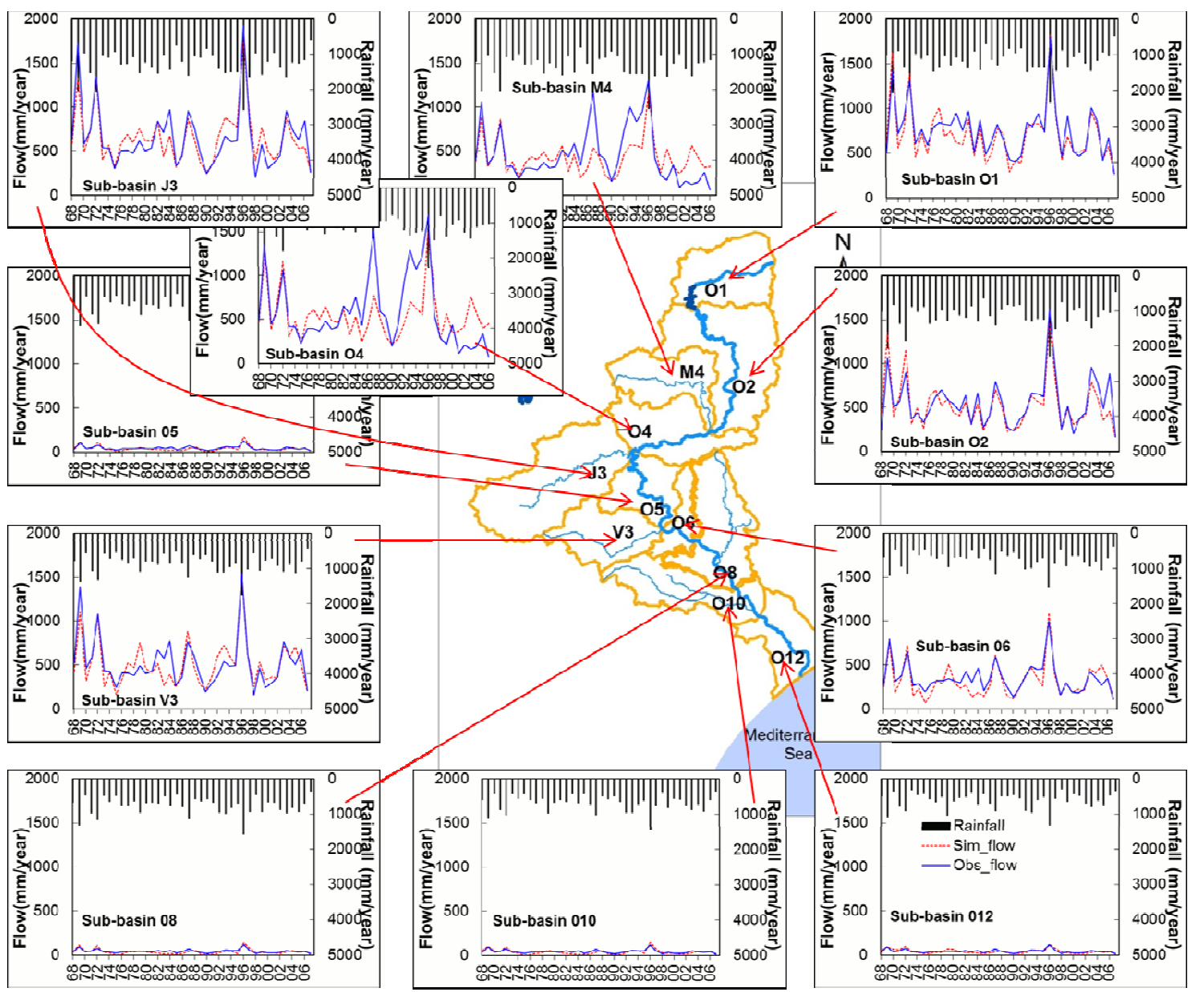

Figure A Comparison of simulated and observed annual flow discharges and rainfall at the 11 sub-river basin from 1968 to 2007. (The model is run at the monthly scale but only annual data are represented)

\begin{tabular}{|c|c|c|c|c|c|c|c|c|c|c|c|}
\hline Sub-basin & 01 & $\mathbf{O 2}$ & M4 & 04 & $\mathbf{J 3}$ & $\mathbf{O 5}$ & $\mathbf{V 3}$ & O6 & $\mathbf{0 8}$ & 010 & 012 \\
\hline Warm up & \multicolumn{11}{|c|}{ 1968-1969 } \\
\hline Calibration & \multicolumn{2}{|c|}{ 1970-2001 } & \multicolumn{2}{|c|}{ 1970-1992 } & \multicolumn{7}{|c|}{ 1970-2001 } \\
\hline $\operatorname{Nash}(\mathbf{Q})$ & 0.86 & 0.89 & 0.75 & 0.78 & 0.85 & 0.85 & 0.80 & 0.72 & 0.55 & 0.46 & 0.36 \\
\hline RMSE (mm) & 23.8 & 19.8 & 20.2 & 24.0 & 28.2 & 28.2 & 26.1 & 19.4 & 2.8 & 3.1 & 3.4 \\
\hline Validation & \multicolumn{2}{|c|}{ 2002-2007 } & \multicolumn{2}{|c|}{ 1993-1995 } & \multicolumn{7}{|c|}{$2002-2007$} \\
\hline $\operatorname{Nash}(Q)$ & 0.93 & 0.80 & 0.47 & 0.54 & 0.80 & 0.72 & 0.78 & 0.40 & 0.69 & 0.58 & 0.40 \\
\hline RMSE (mm) & 16.5 & 29.3 & 42.1 & 50.5 & 29.8 & 1.8 & 25.5 & 20.8 & 1.7 & 2.0 & 2.4 \\
\hline
\end{tabular}

Table A Calibration and validation performances of the hydrological model by sub-basins. 
Appendix D: Demand assumption descriptions

\section{Future urban demand scenario:}

The estimation of the future urban demand for domestic water supply relies on the following main components: the demographic growth, the price of water, climate change or urban water savings. The main assumption presented in section 3.2 and table 2 are further detailed below. More information can be consulted in the report: Vernier, M. and Rinaudo JD (2012) Scénarios d'évolution de la demande en eau potable à l'horizon 2030 dans l'Ouest Hérault. Rapport BRGM/RP-61317-FR. BRGM, Orléans, France. 51 pp http://infoterre.brgm.fr/rapports/RP-61317-FR.pdf (In French)

\section{Demographic growth:}

Between 1990 and 2007, the average demographic growth rate in the French region LanguedocRoussillon, where is located the Orb river basin, was $1.13 \%$, the highest in France ( $0.52 \%$ in average). The French National Institute of Statistics and Economic Studies (INSEE, model Omphale) projected that this growth rate will continue until 2030 even if it will get closer to the other regions. The final demographic growth rate has been established at the "living area" scale (group of municipalities sharing resources, "basin de vie") to harmonize local dynamics (1\% in average).

\section{Water price:}

The current trend in an increase of the price of water (volumetric part) is assumed to continue giving the aging of infrastructures and the need to finance their replacement, but as well due to the strengthening of the environmental and health legislation on the supply of water. From 2004 to 2008, the price of water has increased by $3.3 \%$ per year, whereas the consumer price index increased by 1.9 $\%$ per year. The price of water has then increased faster than inflation at a rate of $1.4 \%$. By projecting this rate, the increase in water price in 2030 has been established at $30 \%$. This increase is expected to act as an incentive to decrease household water consumption and is taken into account in the econometric model (section 2.2.1).

\section{Climate change impact:}

The increase in maximal temperature ( +1.5 to $2{ }^{\circ} \mathrm{C}$ in annual average) is expected to contribute to the increase in household water demand by increasing some outdoor water uses (swimming pool evaporation, garden irrigation) and indoor uses (showers). In the absence of further data about the magnitude of this increase on the study area, we took the 2003 summer heatwave consumption as a first proxy to estimate the impact of climate change on urban water demand. During this year, the water consumption increase by $13 \%$ in comparison to the 6 precedent years with an increase in 
maximum temperature of more than 4 degree $(+20 \%$ in summer). Therefore we assume an increase in the annual average water consumption of $6.5 \%$ and of $10 \%$ in summer.

Water savings:

Between 2004 and 2008, household water consumption in France has decreased by $2 \%$ per year and per habitant to reach 151 liter per capita per day. The decrease corresponds to a change in the tendency until 2004, when water demand increased by $1 \%$ per year per habitant. Over the planning horizon, if we assume that this new trend will continue this could lead to a decrease of $14 \%$ in water consumption. The price increase could explain up to a fifth of this increase (given the econometric model developed), the rest being due to technological improvement of water devices and voluntary water savings. If we deduct as well the decrease in water consumption due to the decrease in the number of people per household (from 2.2 to 2 people per household between 2008 and 2030), the water savings due to technological change and voluntary water savings are estimated to $10 \%$.

Other non-domestic water consumptions increases have been taken as proportional to the population. The efficiency of the water network distribution has been assumed as constant, one of the measures of adaptation being to improve this efficiency.

\section{Future agricultural demand scenario:}

The hypotheses underlying the definition of the agricultural demand scenario rely on the consultation of experts and grey literature at the local regional and national scale. Future cultivated and irrigated areas have been assessed in the case study area to build up a coherent development scenario for the river basin. This scenario assumes an increase in irrigated area by a factor of 4 , mainly due to the development of irrigated vineyard from the current 3300 hectares to more than 17000 hectares. However, this increase relies on assumptions on the availability of water resources, public subsidies and land use planning. Clearly, this scenario represents the development wanted by the agricultural sector without considering the limitations of water resources. The possibility of such development and its cost in terms of adaptation is discussed in the rest of the paper as a trade-offs between the cost of the programme of measures and the level of irrigated agriculture (section 4.4.1).

More information is available on the report Maton M., Girard, C. and Rinaudo, J.D., 2012. Evolution des besoins en eau d'irrigation à l'horizon 2030 dans l'Ouest de l'Hérault Rapport BRGM- RP - 61323 - FR. http://infoterre.brgm.fr/rapports/RP-61323-FR.pdf (In French) 


\section{References}

AERMC (Agence de I'Eau Rhône Corse Méditerranée), 2009. Schéma directeur d'aménagement et de gestion des eaux du bassin Rhône-Méditerranée. Vers le bon état des milieux aquatiques. Agence de l'Eau Rhône, Méditerranée, Corse. http://www.rhonemediterranee.eaufrance.fr/docs/dce/sdage/docs-officiels/BD/RM_Sdage_BD.pdf (In French)

Allen, R.G., Pereira, L.S., Raes, D., Smith, M, 1998. Crop Evapotranspiration-Guidelines for computing Crop Water Requirements. FAO Irrigation and drainage paper 56. Rome, Italy: Food and Agriculture Organization of the United Nations. ISBN 92-5-1042

Andreu, J., Capilla, J., Sanchís, E., 1996. AQUATOOL, a generalized decision-support system for water-resources planning and operational management. Journal of Hydrology 177, 269-291.

Arnell, N.W., 2004. Climate change and global water resources: SRES emissions and socioeconomic scenarios. Global Environ. Change 14, 31-52.

Barsugli, J., Vogel, J., Kaatz, L., Smith, J., Waage, M., Anderson, C., 2012. Two Faces of Uncertainty: Climate Science and Water Utility Planning Methods. J. Water Resour. Plann. Manage. $138,389-395$.

Bates, B.C., Z.W. Kundzewicz, S. Wu and J.P. Palutikof, 2008. Climate Change and Water. Technical Paper of the Intergovernmental Panel on Climate Change, IPCC Secretariat, Geneva, 210 pp.

Bauman, D.D., Boland, J.J., Haneman, W.M., 1998. Urban water demand management and planning. McGraw-Hill, New-York.

Brown C., Wilby R. L. ,2012. An alternate approach to assessing climate risks. Eos 93, 401-402.

Brown, C. Ghile, Y . Laverty, M and Li, K, 2012. Decision scaling: Linking bottom-up vulnerability analysis with climate projections in the water sector WATER RESOURCES RESEARCH, 48, W09537, doi:10.1029/2011WR011212, 2012 
Caballero, Y., S. Voirin-Morel, F. Habets, J. Noilhan, P. LeMoigne, A. Lehenaff, and A. Boone, 2007. Hydrological sensitivity of the Adour-Garonne river basin to climate change, Water Resour. Res., 43, W07448, doi:10.1029/2005WR004192.

Caballero Y. and Girard C., 2012. Impact du changement climatique sur la ressource en eau du bassin versant de l'Orb. Rapport BRGM/RP-61319-FR. 40 p., 16 ill. http://infoterre.brgm.fr/rapports/RP-61319-FR.pdf (In French)

Chazot, S., 2011. Perspectives d'évolution de la gestion des volumes stockés dans le barrage des Monts d'Orb. Rapport final, Novembre 2011, BRL Ingénierie. http://www.vallees-orb-libron.fr/wpcontent/uploads/2012/12/etude-gestion-Monts-Orb-Rapport-V16.pdf (In French)

De Roo, A., Burek, P., Gentile, A., Udias, A, Bouraoui, F., Aloe, A. Bianchi, A. La Notte, A., Kuik, O., Elorza Tenreiro, J., Vandecasteele, I., Mubareka, S., Baranzelli, C., Van Der Perk, M., Lavalle, C., Bidoglio, G., 2012. A multi-criteria optimisation of scenarios for the protection of water resources in Europe, Support to the EU Blueprint to Safeguard Europe's Waters, JRC Scientific and policy report, European Commission. http://publications.jrc.ec. europa.eu/repository/handle/111111111/26672

Draper, A. J., M. W. Jenkins, K. W. Kirby, J. R. Lund, and R. E. Howitt, 2003. Economic engineering optimization for California water management, J. Water Resour. Plann. Manage., 129(3), 155-164

EC (European Commission), 2012. A Blueprint to Safeguard Europe's Water Resources, European Commission, Brussels, 14.11.2012, COM(2012) 673 final.

Ejeta, M.Z., and Mays, L.W., 2005, Regional Water supply planning and capacity expansion models, in: Larry W Mays, 2005, Water Resource Systems Management Tools. McGraw-Hill. Available from: http://www.public.asu.edu/ /wmays/research_paper.htm

Ghaffour, N., Missimer, T.M., Amy, G.L., 2013. Technical review and evaluation of the economics of water desalination: Current and future challenges for better water supply sustainability. Desalination 309, 197-207.

Giorgi, F., Lionello, P., 2008. Climate change projections for the Mediterranean region. Global Planet. Change 63, 90-104.

Gippel, C., J., and Stewardson, J., 1998. Use of wetted perimeter in defining minimum environmental flows, Regulated Rivers: Research \& Management, 14, 53-67.

Hamilton, S. H., El Sawah, S., Guillaume, J.H. A., Jakeman, A.J., Pierce, S.A., 2015. Integrated assessment and modelling: Overview and synthesis of salient dimensions. Environmental Modelling \& Software, 64, 215-229, doi:10.1016/j.envsoft.2014.12.005

Harou, J.J., Pulido-Velazquez, M., Rosenberg, D.E., Medellín-Azuara, J., Lund, J.R., Howitt, R.E., 2009. Hydro-economic models: Concepts, design, applications, and future prospects. Journal of Hydrology 375, 627-643.

Hashimoto, T., Stedinger, J.R., Loucks, D.P., 1982. Reliability, resiliency, and vulnerability criteria for water resource system performance evaluation. Water Resour. Res. 18, 14-20.

Heinz, I., Pulido-Velazquez, M., Lund, J.R., Andreu, J., 2007. Hydro-economic modeling in river basin management: Implications and applications for the European water framework directive. Water Resour. Manage. 21, 1103-1125.

Hoang, T., Maton, L. Caballero, Y. et Rinaudo J-D. 2012. Impact du changement climatique sur le besoin en eau d'irrigation dans l'Ouest de I'Hérault. Rapport Brgm RP-61311-FR. 36 pp (In French)

Hunt, A., Watkiss, P., 2011. Climate change impacts and adaptation in cities: A review of the literature. Clim. Change 104, 13-49. 
Hurd, B.H., Coonrod, J., 2012. Hydro-economic consequences of climate change in the upper Rio Grande. Climate Research 53, 103-118.

Jakeman, A.J., Letcher, R.A., 2003. Integrated assessment and modelling: Features, principles and examples for catchment management. Environmental Modelling and Software 18, 491-501. http://dx.doi.org/10.1016/S1364-8152(03)00024-0

Jeuland, M., and D. Whittington, 2014. Water resources planning under climate change: Assessing the robustness of real options for the Blue Nile, Water Resour. Res., 50, 2086-2107, doi: 10.1002/2013WR013705.

Knutti, R., Furrer, R., Tebaldi, C., Cermak, J., Meehl, G.A., 2010. Challenges in combining projections from multiple climate models. J. Clim. 23, 2739-2758.

Kragt,M.E.; Robson,B.J.; Macleod,C.J.A., 2013. Modellers' role in structuring integrative research projects. Environmental Modelling and Software, 2013, 39, 322-330

Labadie, J.W., 2004. Optimal operation of multireservoir systems: State-of-the-art review. J. Water Resour. Plann. Manage. 130, 93-111.

Lempert, R.J., Groves, D.G., 2010. Identifying and evaluating robust adaptive policy responses to climate change for water management agencies in the American west. Technological Forecasting and Social Change 77, 960-974.

Lamouroux N., 2002. Estimhab: estimating in-stream habitat quality changes associated with river management. Shareware \& User's guide, Cemagref, Lyon.

http://www.lyon.cemagref.fr/bea/lhq/lhq.html .

Letcher, R.A., Croke, B.F.W., Jakeman, A.J., 2007. Integrated assessment modelling for water resource allocation and management: A generalised conceptual framework. Environmental Modelling and Software 22, 733-742.

Loucks, D. P., Stedinger, J. R., and Haith, D. A. 1981. Water resources systems planning and analysis. Englewood Cliffs, N.J.: Prentice-Hal.

Loucks, D.P., 1997. Quantifying trends in system sustainability. Hydrological Sciences Journal 42, 513-530.

Madani, K., 2010. Game theory and water resources. Journal of Hydrology 381, 225-238.

Mariotti, A., Zeng, N., Yoon, J.-., Artale, V., Navarra, A., Alpert, P., Li, L.Z.X., 2008. Mediterranean water cycle changes: Transition to drier 21st century conditions in observations and CMIP3 simulations. Environmental Research Letters 3. DOI 10.1088/1748-9326/3/4/044001

Martin-Carrasco, F., Garrote, L., Iglesias, A., Mediero, L., 2013. Diagnosing Causes of Water Scarcity in Complex Water Resources Systems and Identifying Risk Management Actions. Water Resour. Manage. 27, 1693-1705. DOI 10.1007/s11269-012-0081-6

Maton M., Girard, C. and Rinaudo, J.D., 2012. Evolution des besoins en eau d'irrigation à I'horizon 2030 dans l'Ouest de l'Hérault Rapport BRGM- RP - 61323 - FR http://infoterre.brgm.fr/rapports/RP-61323-FR.pdf (In French)

Matrosov, E.S., Padula, S., Harou, J.J. (2013) Selecting Portfolios of Water Supply and Demand Management Strategies Under Uncertainty-Contrasting Economic Optimisation and 'Robust Decision Making' Approaches, Water Resources management , 27(4), 1123 - 1148. 10.1007/s11269-0120118-x. 
MEEDDT (Ministère de l'écologie, de l'énergie, du développement durable et de l'aménagement du territoire), 2008. Circulaire du 30 juin 2008 relative à la résorption des déficits quantitatifs en matière de prélèvement d'eau et gestion collective des prélèvements d'irrigation NOR : DEVO0815432C, Bulletin officiel du Ministère de l'écologie, de l'énergie, du développement durable et de l'aménagement du terittoire, Paris, 2008 (In French)

Medellín-Azuara, J.; Harou, J. J.; Olivares, M. A.; Madani, K.; Lund, J. R.; Howitt, R. E.; Tanaka, S. K.;Jenkins, M. W.; Zhu, T. Adaptability and adaptations of California's water supply system to dry climate warming. Clim. Change, 2008, 87, 1, 75-90

Mollinga, P.P., 2009. Towards the transdisciplinary engineer: Incorporating ecology, equity and democracy concerns into water professionals' attitudes, skills and knowledge. Irrigation and Drainage 58, S195-S204.

Mouelhi, S., Michel, C., Perrin, C., Andréassian, V., 2006. Stepwise development of a twoparameter monthly water balance model. Journal of Hydrology 318, 200-214. doi:10.1016/j.jhydrol.2005.06.014

Nash,J.E., and Sutcliffe,J.V., 1970. River flow forecasting through conceptual models, J. Hydrol., $10(3), 282-290$.

Newlin, B. D., M. W. Jenkins, J. R. Lund, and R. E. Howitt, 2002. Southern California water markets: Potential and limitations, J. Water Resour. Plann. Manage., 128(1), 21-32.

O'Laoghaire, D. T., and Himmelblau, D. M., 1974. Optimal expansion of a water resources system. - With 273 pp. New York and London: Academic Press. ISBN 0-12-525450-4.

Pagé, C. and Terray, L., 2010. Nouvelles projections climatiques à échelle fine sur la France pour le 21ème siècle : les scénarii SCRATCH2010. Technical Report TR/CMGC/10/58, SUC au CERFACS, URA CERFACS/CNRS No1875CS, Toulouse, France (http://www.cerfacs.fr/ page/work/scratch/). (In French)

Poff, N.L., Allan, J.D., Bain, M.B., Karr, J.R., Prestegaard, K.L., Richter, B.D., Sparks, R.E., Stromberg, J.C., 1997. The natural flow regime: A paradigm for river conservation and restoration. Bioscience 47, 769-784.

Pohl, C., 2005. Transdisciplinary collaboration in environmental research. Futures 37, 1159-1178.

Postel S. Richter B., 2003. Rivers for Life: Managing Water for People and Nature. Island Press, Washington, DC.

Pouget, L., Escaler, I., Guiu, R., Mc Ennis, S., Versini, P.-., 2012. Global Change adaptation in water resources management: The Water Change project. Sci. Total Environ. 440, 186-193.

Pulido-Velazquez, M., Alvarez-Mendiola, E., Andreu, J., 2013. Design of efficient water pricing policies integrating basinwide resource opportunity costs. J. Water Resour. Plann. Manage. 139, 583-592.

Pulido-Velazquez, M., Andreu, J., Sahuquillo, A., Pulido-Velazquez, D., 2008. Hydro-economic river basin modelling: The application of a holistic surface-groundwater model to assess opportunity costs of water use in Spain. Ecol. Econ. 66, 51-65.

Pulido-Velazquez, M., M. W. Jenkins, and J. R. Lund, 2004, Economic values for conjunctive use and water banking in southern California, Water Resour. Res., 40, W03401, doi: $10.1029 / 2003$ WR002626

Pushpalatha, R., Perrin, C., Le Moine, N., Andréassian, V., 2012. A review of efficiency criteria suitable for evaluating low-flow simulations, Journal of Hydrology 420-421 171-182, doi:10.1016/j.jhydrol.2011.11.055 
Quevauviller,P.; Barceló,D.; Beniston,M.; Djordjevic,S.; Harding,R.J.; Iglesias,A.; Ludwig,R.; Navarra,A.;Navarro Ortega,A.; Mark,O.; Roson,R.; Sempere,D.; Stoffel,M.; van Lanen,H.A.J.; Werner,M.; 2012, Integration of research advances in modelling and monitoring in support of WFD river basin management planning in the context of climate change. Sci.Total Environ., 440, 167177

Refsgaard, J.C., van der Sluijs, J.P., Højberg, A.L., Vanrolleghem, P.A., 2007. Uncertainty in the environmental modelling process - A framework and guidance. Environmental Modelling and Software 22, 1543-1556. http://dx.doi.org/10.1016/j.envsoft.2007.02.004

Reuss, M., 2003. Is It Time to Resurrect the Harvard Water Program?, EDITORIAL , J. Water Resour. Plann. Manage., 129, 5 , 357-360. EDITORIAL

Riegels, N., Pulido-Velazquez, M., Doulgeris, C., Sturm, V., Jensen, R., Møller, F., Bauer-Gottwein, P., 2013. Systems analysis approach to the design of efficient water pricing policies under the EU water framework directive. J. Water Resour. Plann. Manage. 139, 574-582.

Rinaudo, J.-., Neverre, N., Montginoul, M., 2012. Simulating the impact of pricing policies on residential water demand: A southern France case study. Water Resour. Manage. 26, 2057-2068.

Rinaudo, J.-D., Maton, L., Terrason, I., Chazot, S., Richard-Ferroudji, A., Caballero, Y., $2013 a$. Combining scenario workshops with modeling to assess future irrigation water demands. Agric. Water Manage. 130, 103-112.

Rinaudo, J-D, Noel, Y., Marchal, J.-P., Lamotte, C., 2013b. Evaluation du coût de mobilisation de nouvelles ressources en eau souterraine dans I'Ouest de I'Hérault. Rapport BRGM-RP- 61794-FR http://infoterre.brgm.fr/rapports/RP-61794-FR.pdf (In French)

Rosenthal, E., 2012. GAMS, A User's Guide Tutorial by Richard E. Rosenthal, GAMS Development Corporation, Washington, DC, USA.

Salas-Mélia, D., F. Chauvin, M. Déqué, H. Douville, J.F. Gueremy, P. Marquet, S. Planton, J.F. Royer and S. Tyteca, 2005. Description and validation of the CNRM-CM3 global coupled model, CNRM working note 103. http://www.cnrm.meteo.fr/scenario2004/references eng.html (accessed 20/01/2014)

SMVO (Syndicat Mixte de la Vallée de I'Orb), 2013. Contrat de rivière Orb-Libron, 2011-2015, Dossier définitif, Dossier M001 803039 / EV. http://www.vallees-orb-libron.fr/wpcontent/uploads/2012/12/dossier-definitif-contrat-riviere-orb-libron-11-15.pdf (In French)

Tanaka,S.K., Zhu,T., Lund,J.R., Howitt,R.E., Jenkins,M.W., Pulido,M.A., Tauber,M., Ritzema, R.S., Ferreira, I.C. Titre, 2006. Climate warming and water management adaptation for California, Clim.Change, 2006, 76, 3-4, 361-387

Thivet, G. and Fernandez, S., 2012. Water Demand Management: The Mediterranean Experience. Technical focus paper, Plan Bleu \& Global Water Partnership, http://planbleu.org/sites/default/files/publications/water demand management plan bleu gwp.pd $\underline{f}$

Vachala, S., 2008. Evaporation sur les retenus EDF du Sud de la France, Électricité De France. Division Technique Générale, Service ressources en eau.

Vernier, M. and Rinaudo JD (2012) Scénarios d'évolution de la demande en eau potable à I'horizon 2030 dans I'Ouest Hérault. Rapport BRGM/RP-61317-FR. BRGM, Orléans, France. 51 pp http://infoterre.brgm.fr/rapports/RP-61317-FR.pdf (In French)

Vidal, J.-P, Martin, E., Franchistéguy, L., Baillon, M., Soubeyroux, J.-M, 2010. A 50-year highresolution atmospheric reanalysis over France with the Safran system. Int. J. Climatol. 30, 16271644. doi:10.1002/joc.2003 
Vier E. and Aigoui. F. 2011. Etude de définition des débits d'étiage de référence pour la mise en oeuvre d'une gestion quantitative de la ressource en eau dans le bassin de l'Orb. Rapport provisoire phases 1 et 2. Avril 2011. Syndicat mixte de la vallée de I'Orb. (In French).

Wilby, R.L., Dessai, S., 2010. Robust adaptation to climate change. Weather 65, 180-185. DOI: 10.1002/wea.543

Zhou, Y., Tol, R.S.J., 2005. Evaluating the costs of desalination and water transport. Water Resour. Res. 41, 1-10. 


\section{Highlights:}

- An interdisciplinary modelling framework is presented to analyse the effects of global change on water resource systems at the basin scale.

- Present and future urban and agricultural water demands, as well as climate change scenario, are integrated into a river basin management model.

- Future supply and demand management measures are selected using least-cost optimisation.

- Trade-offs between the cost of adaptation measures, irrigated agriculture development, and environmental requirements are quantified.

- Insights to improved integrated water management at basin scale through interdisciplinary modelling are provided. 


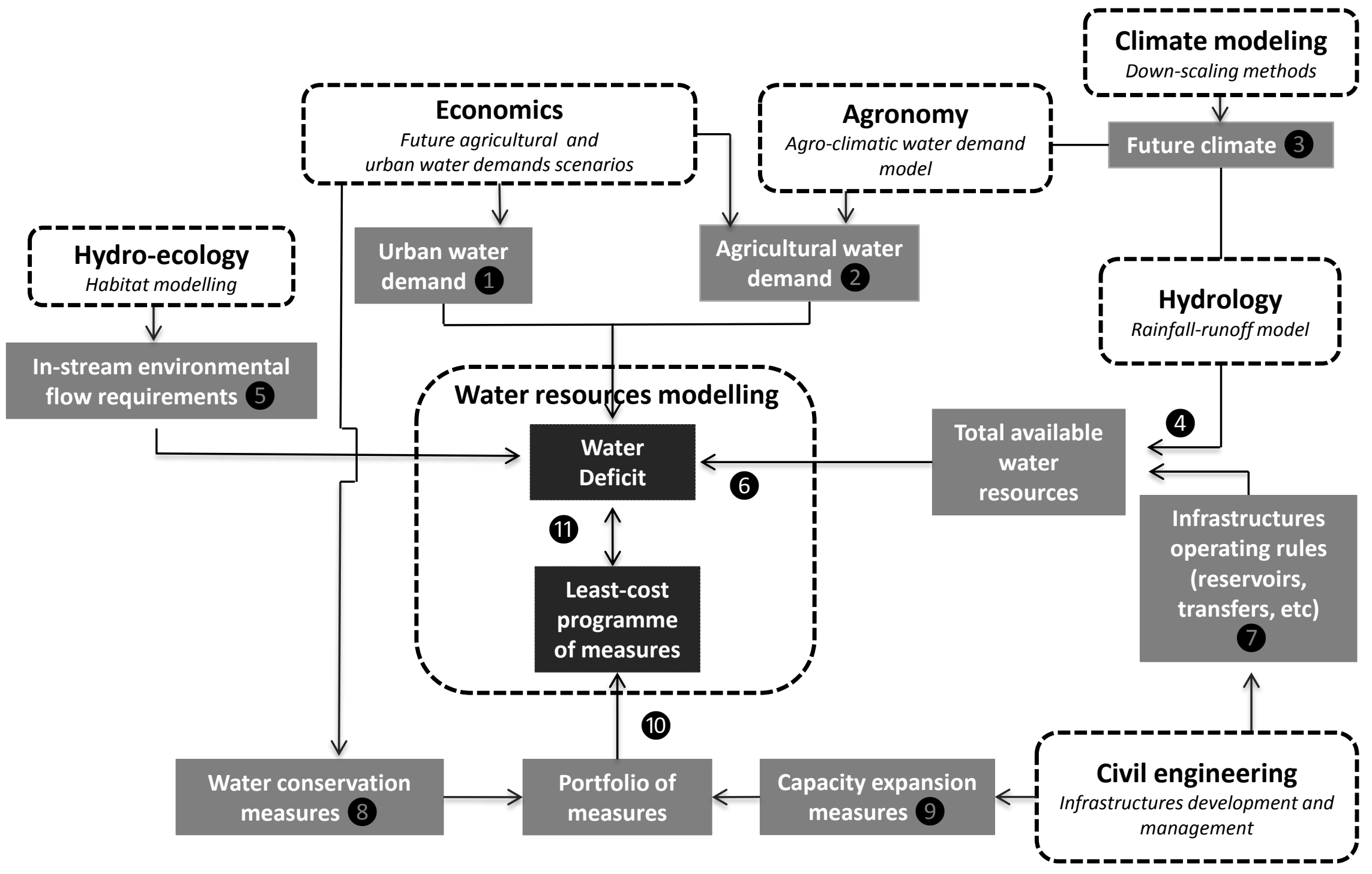




\section{Figure 2}

Click here to download high resolution image

\section{Legend}

Limit of the basin and sub-basin

^ Agricultural demand area

Urban demand area

- Pumping station

un Water transfer

Main city
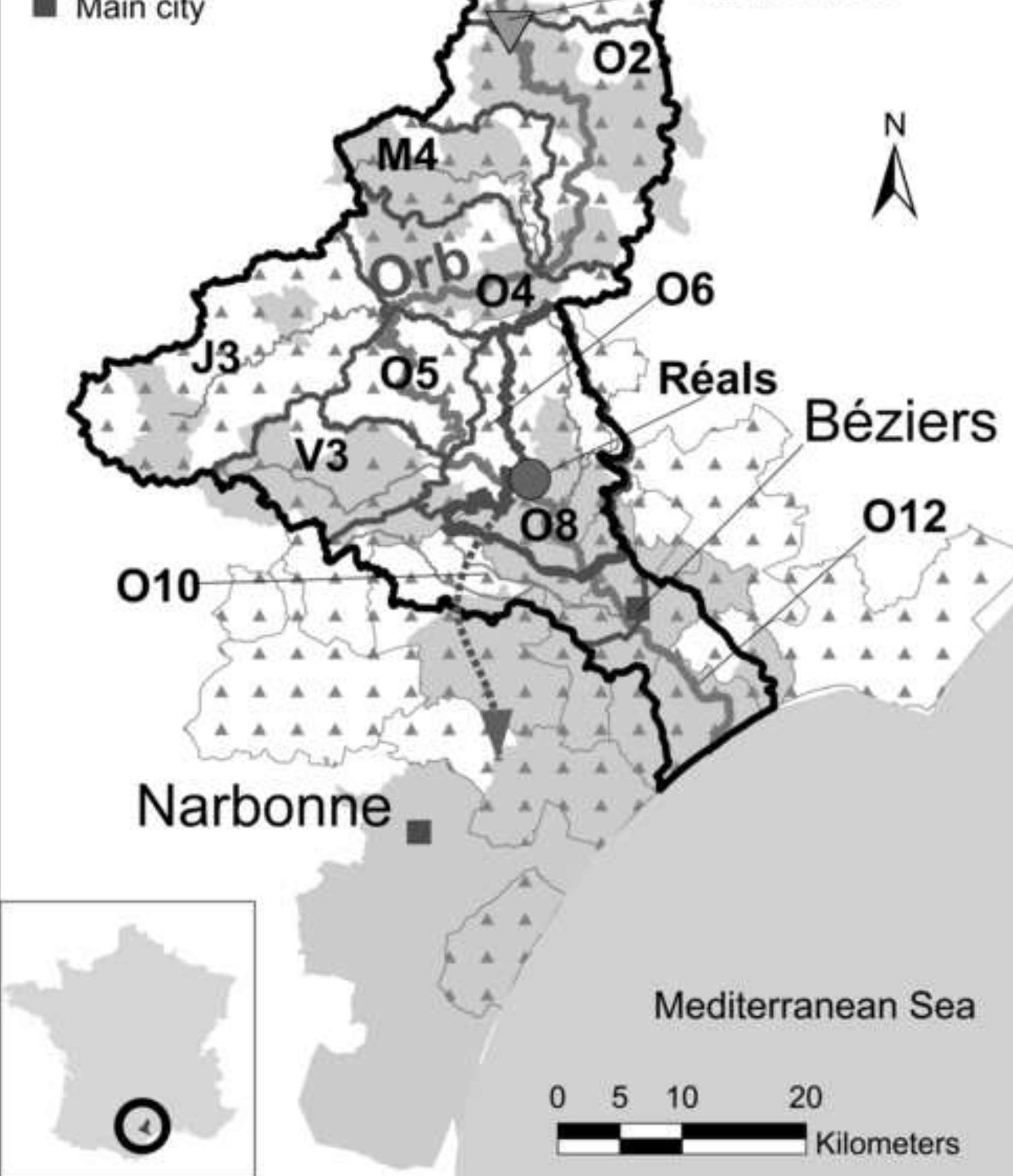

Mediterranean Sea

$\begin{array}{llll}0 & 5 & 10 & 20\end{array}$

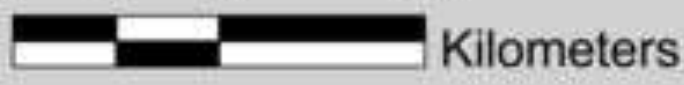




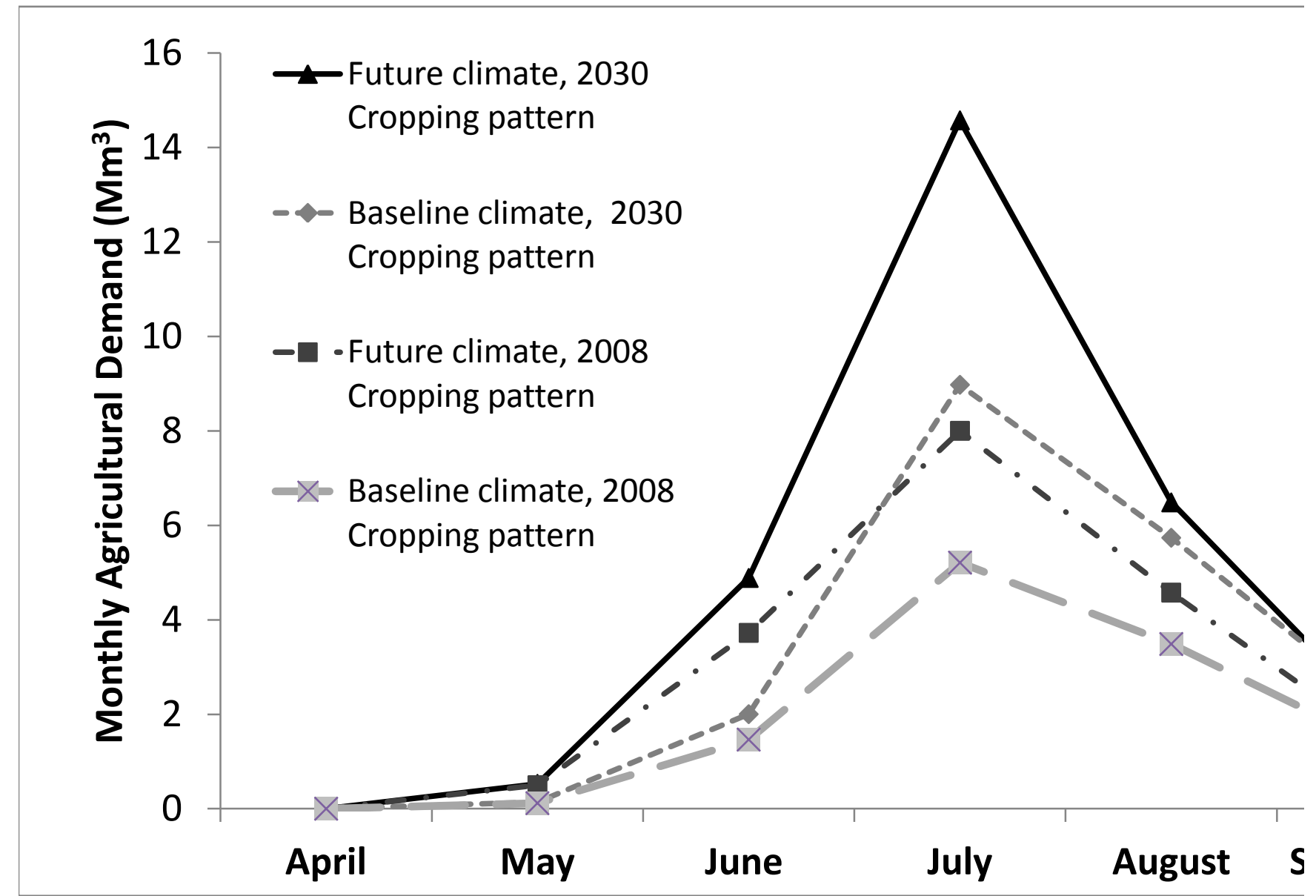


Total future demand by node (\% of total basin demand)
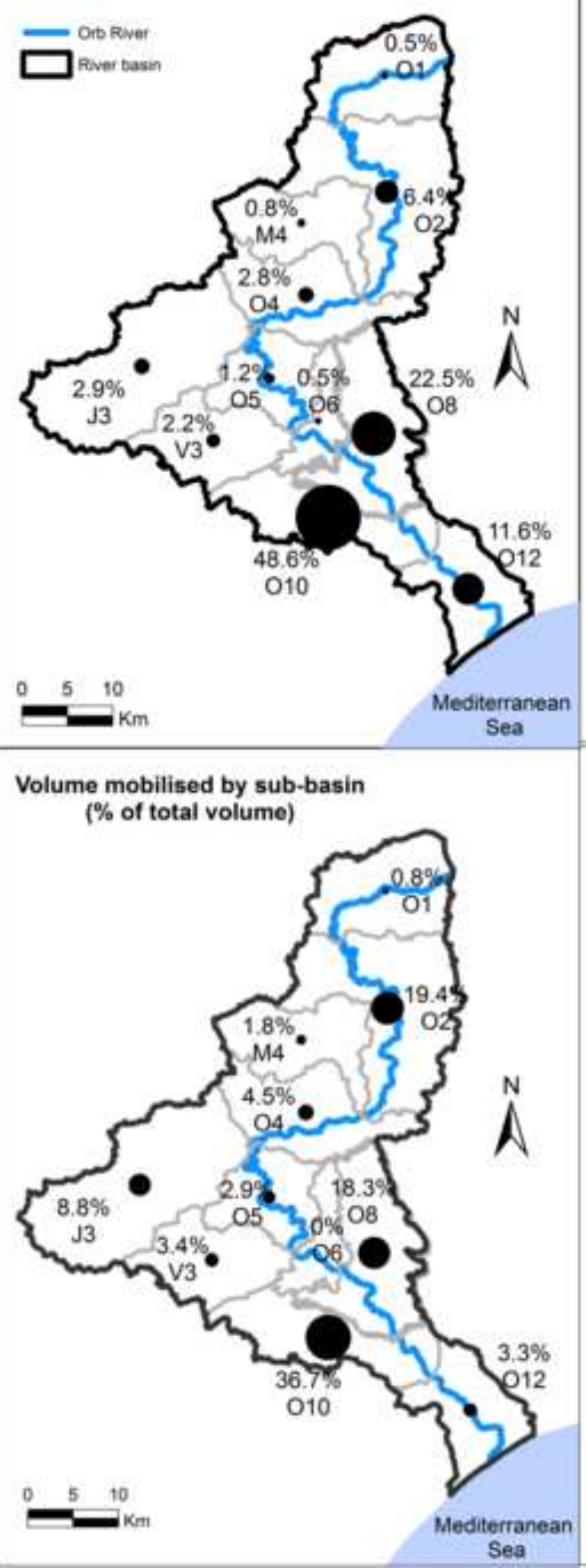

Agricultural Deficit Index by sub-basin ( $\%$ of deficit on agricultural demand)

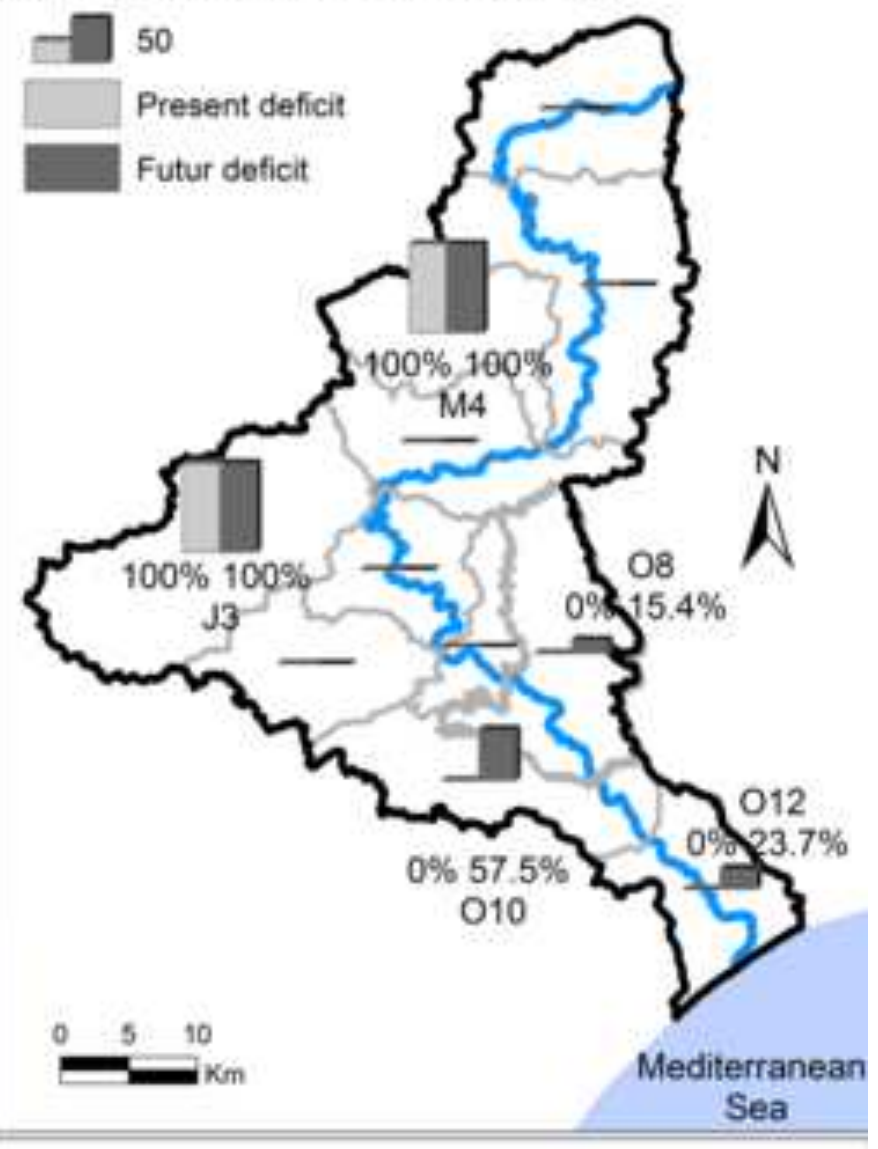

Cost by sub-basin

( $\%$ of total cost)

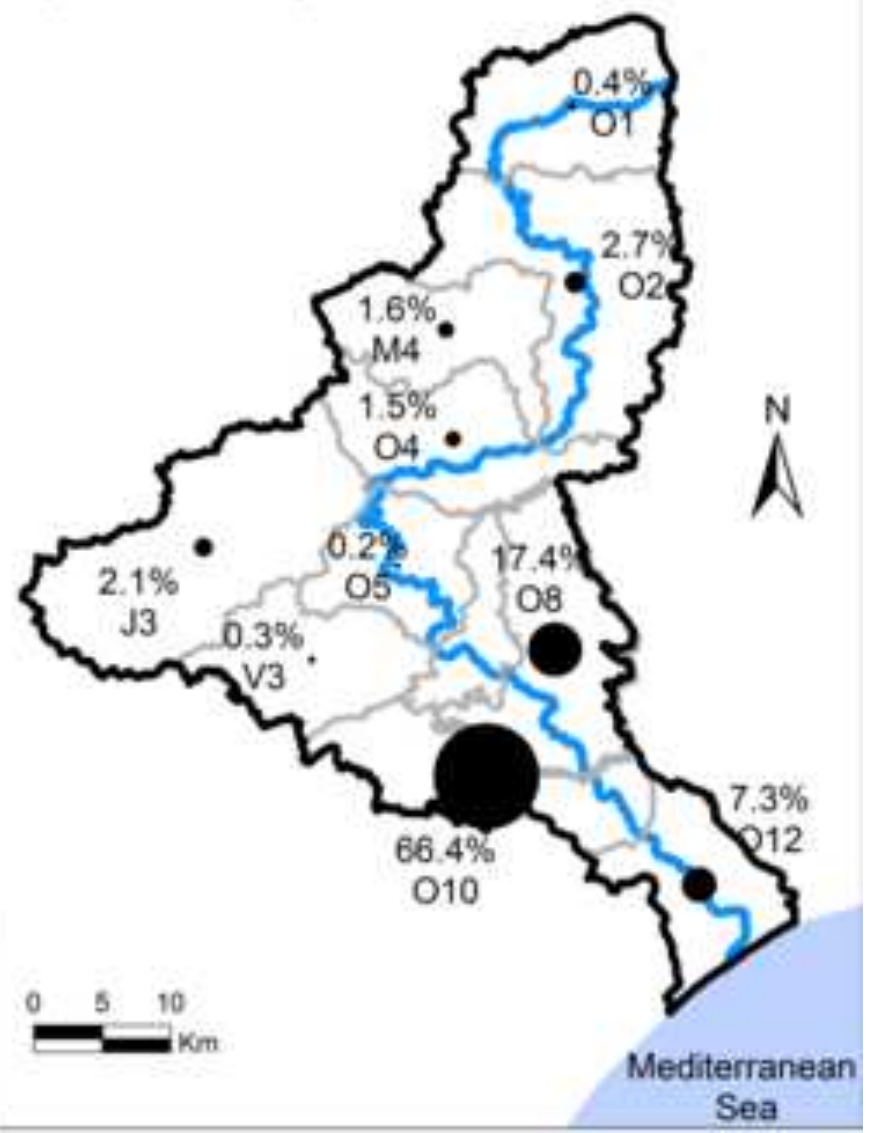




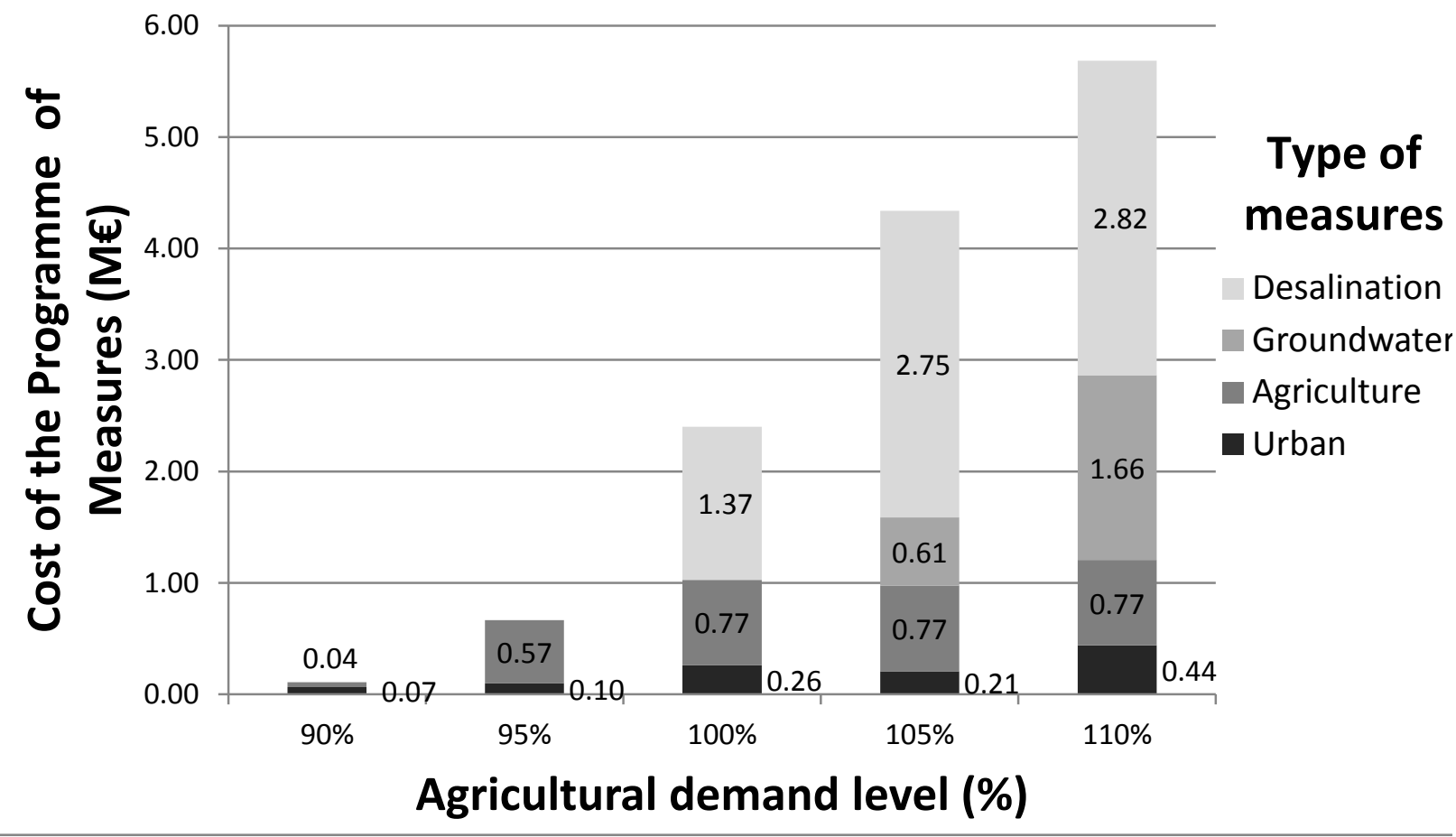




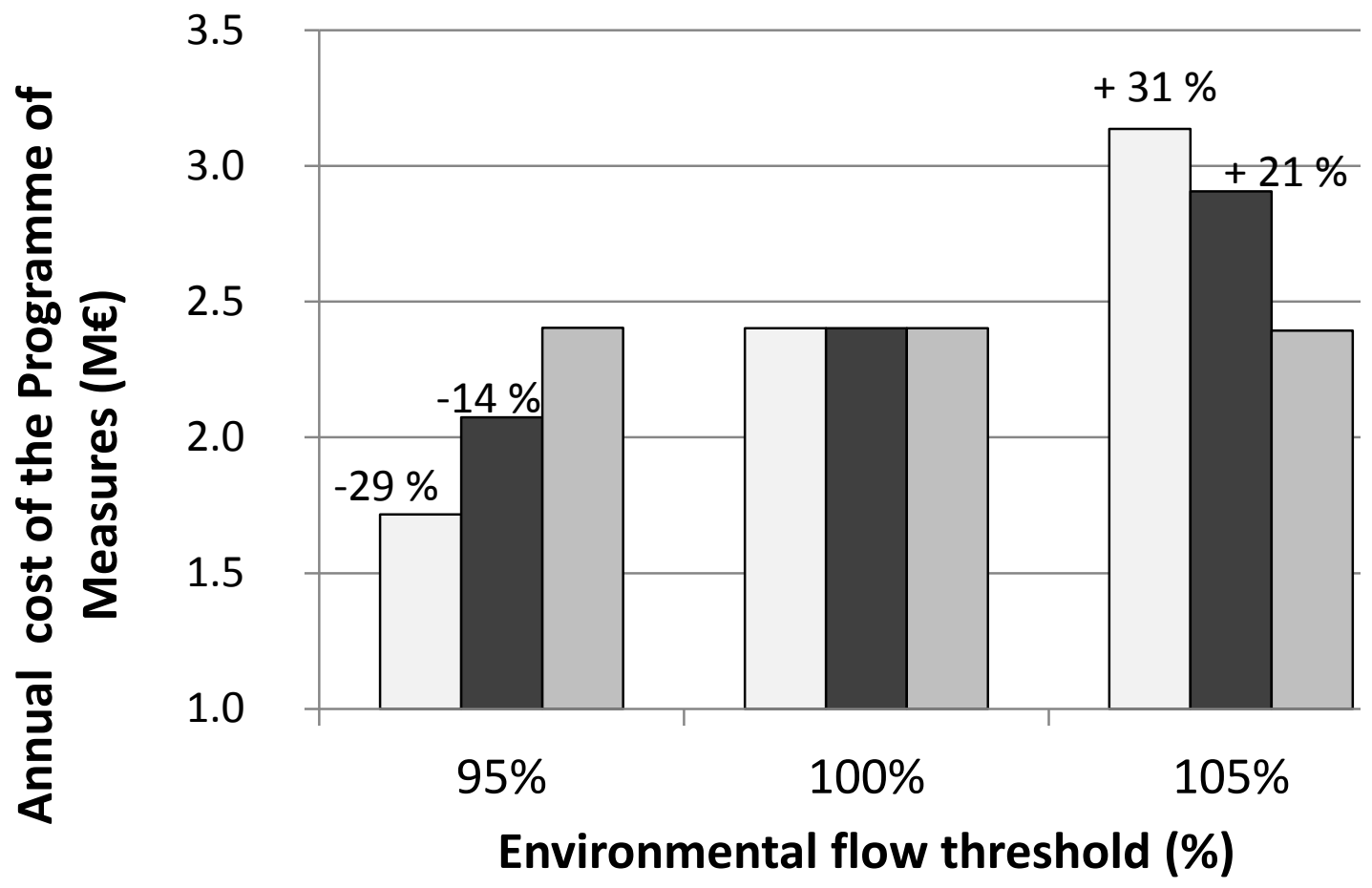




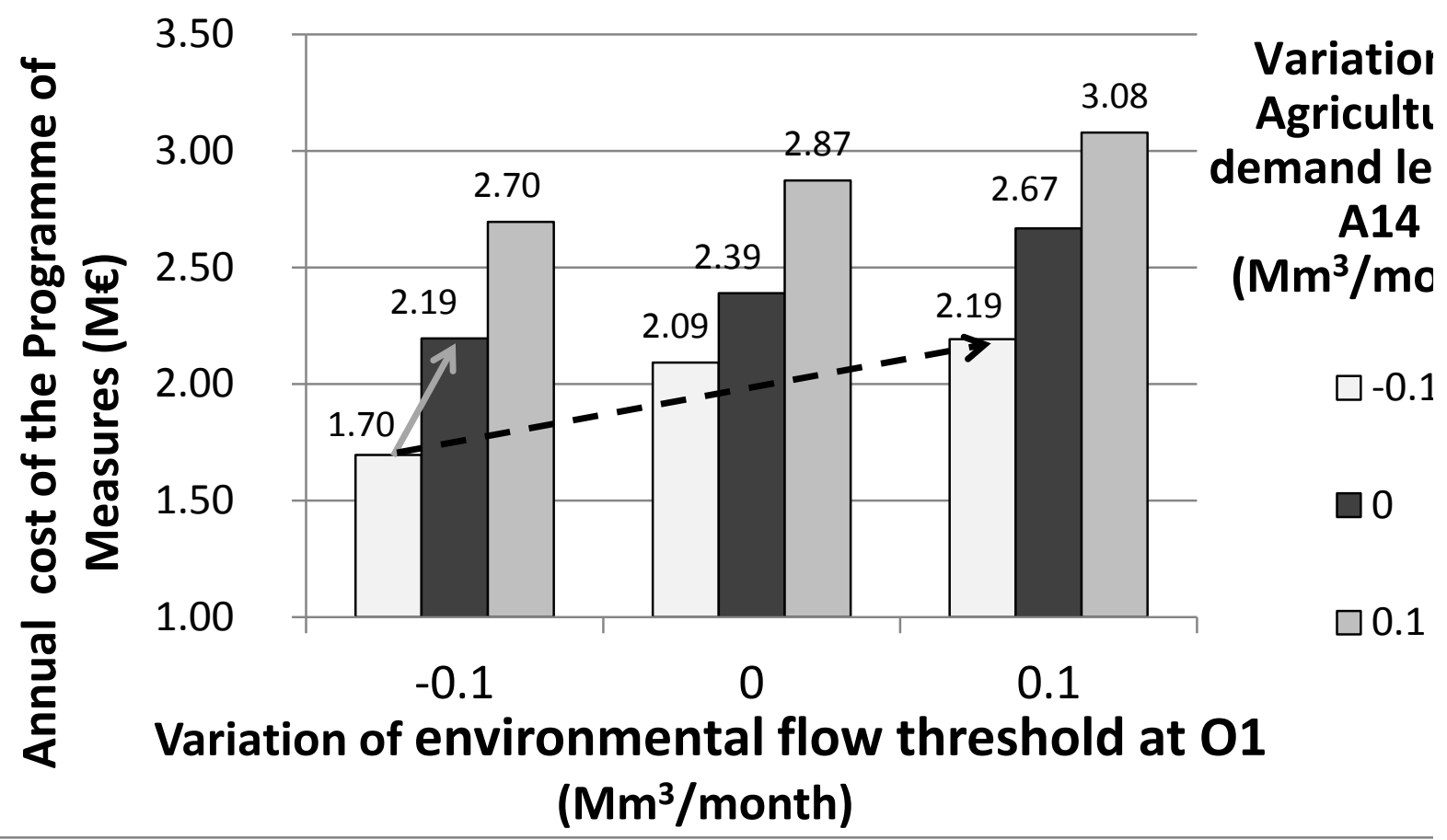




\begin{tabular}{ccccccc}
\hline Demand $\left(\mathrm{Mm}^{3}\right)$ & Urban & Agricultural & Environmental & Total & $\begin{array}{c}\text { Resources } \\
\left(\mathrm{Mm}^{3}\right)\end{array}$ & $\begin{array}{c}\text { Demand/resources } \\
(\%)\end{array}$ \\
\hline $\begin{array}{c}\text { Baseline } \\
\text { Baseline }\end{array}$ & 19.2 & 11.6 & 43.0 & 73.8 & $374^{\mathrm{b}}$ & $19.7 \%$ \\
$\begin{array}{c}\text { summer } \\
\text { Future }\end{array}$ & 7.8 & 10.8 & 14.5 & 33.1 & $55^{\mathrm{b}}$ & $60.2 \%$ \\
\hline $\begin{array}{c}\text { Future } \\
\text { summer }\end{array}$ & 8.9 & 21.9 & 43.0 & 93.2 & $276^{\mathrm{b}}$ & $33.7 \%$ \\
\hline
\end{tabular}

a. The summer period corresponds to four months in the summer (mid-May to mid-September)

b. In this case, the resources are estimated for a dry year with a 5-year return period at the outflow of the basin

Table 1: Annual and summer water balance of the Orb river basin baseline and future scenarios 


\begin{tabular}{lll}
\hline Demand & Urban & Agricultural \\
\hline
\end{tabular}

$+30 \%$ of water price

$25 \%$ of the vineyard is irrigated

- $10 \%$ due to savings

(5\% in 2008)

Main assumptions $+6.5 \%$ due to climate change;

$+100 \%$ of market gardening

Constant household incomes

- $50 \%$ of orchards

Constant irrigation efficiency

Table 2 Main assumptions of the demand forecasting models and results at river-basin scale. 


\begin{tabular}{|c|c|c|c|c|c|c|c|c|c|c|c|c|c|}
\hline \multicolumn{2}{|c|}{ Sub-basin } & 01 & $\mathbf{O 3}$ & M4 & 04 & J3 & 05 & $\mathbf{V 3}$ & 06 & O8 & 010 & 012 & Basin \\
\hline \multirow{2}{*}{$\begin{array}{c}\text { Low-Flow } \\
\text { (Mm per } \\
\text { month) }\end{array}$} & $\begin{array}{c}\text { Baseline } \\
\text { (1971- } \\
\text { 2000) }\end{array}$ & 1.07 & 0.75 & 0.15 & 0.42 & 0.89 & 0.03 & 0.74 & 0.18 & 0.05 & 0.06 & 0.10 & 4.52 \\
\hline & $\begin{array}{c}\text { Future } \\
\text { (2046- } \\
\text { 2065) }\end{array}$ & 0.66 & 0.47 & 0.10 & 0.34 & 0.71 & 0.02 & 0.69 & 0.18 & 0.03 & 0.04 & 0.05 & 3.41 \\
\hline Variation & & $-38 \%$ & $-37 \%$ & $-29 \%$ & $-20 \%$ & $-20 \%$ & $-24 \%$ & $-7 \%$ & $-1 \%$ & $-40 \%$ & $-38 \%$ & $-55 \%$ & $-25 \%$ \\
\hline
\end{tabular}

Table 3: 5-year monthly low-flow (QMNA5) by sub-basin under baseline and future scenarios 


\begin{tabular}{|c|c|c|c|c|}
\hline & Description of measure & $\begin{array}{c}\text { Maximum } \\
\text { annual volume } \\
\text { available in } \\
2030\left(\mathrm{Mm}^{3}\right)\end{array}$ & $\begin{array}{c}\text { Average } \\
\text { annualized } \\
\text { unit cost } \\
\left(€ / \mathbf{m}^{3}\right)\end{array}$ & $\begin{array}{c}\text { UDU/AD } \\
\text { U affected } \\
\text { by the } \\
\text { measure }\end{array}$ \\
\hline \multicolumn{5}{|c|}{$\begin{array}{c}\text { Water conservation measures } \\
\text { (Demand side) }\end{array}$} \\
\hline MU1 & $\begin{array}{l}\text { Reduction of leaks in urban water } \\
\text { distribution networks }\end{array}$ & 3.28 & 0.77 & 37 \\
\hline MU2 & $\begin{array}{l}\text { Installation of water conservation } \\
\text { devices (faucet aerators, shower flow } \\
\text { reducer, etc.) by households }\end{array}$ & 0.36 & 0.56 & 62 \\
\hline MU3 & $\begin{array}{l}\text { Water consumption audits for single } \\
\text { family houses and change in appliances }\end{array}$ & 0.52 & 1.16 & 62 \\
\hline MU4 & $\begin{array}{l}\text { Same as U3 for multifamily housing } \\
\text { units }\end{array}$ & 0.51 & 1.64 & 33 \\
\hline MU5 & $\begin{array}{l}\text { Installation of automated reading } \\
\text { meters and use of seasonal water tariffs } \\
\text { to reduce peak season demand }\end{array}$ & 0.83 & 0.66 & 62 \\
\hline MU6 & $\begin{array}{l}\text { Installation of water saving devices in } \\
\text { hotels (faucet aerators, toilet flushes) }\end{array}$ & 0.04 & 0.61 & 20 \\
\hline MU7 & $\begin{array}{l}\text { Water consumption audits of campsites } \\
\text { and holiday parks. Installation of low } \\
\text { flow flushes / showers, leakage } \\
\text { detection in campsite distribution } \\
\text { network, etc. }\end{array}$ & 0.18 & 1.55 & 10 \\
\hline MU8 & $\begin{array}{l}\text { Replacement of water intensive } \\
\text { landscapes with xeric vegetation } \\
\text { (public gardens) }\end{array}$ & 0.59 & 0.68 & 62 \\
\hline MU9 & $\begin{array}{l}\text { Replacement of irrigated lawns with } \\
\text { artificial turf for sport grounds }\end{array}$ & 0.43 & 1.95 & 7 \\
\hline MA1 & $\begin{array}{l}\text { Conversion of gravity irrigation } \\
\text { systems to pressurized / sprinkler } \\
\text { irrigation }\end{array}$ & 0.81 & 0.16 & 7 \\
\hline \multirow[t]{2}{*}{ MA2 } & $\begin{array}{l}\text { Development of drip-feed irrigation at } \\
\text { farm level in all pressurized irrigation } \\
\text { systems }\end{array}$ & 1.56 & 0.54 & 11 \\
\hline & $\begin{array}{c}\text { Capacity expansion measures } \\
\text { (Resource side) }\end{array}$ & & & \\
\hline GW & $\begin{array}{l}\text { Substitution of water intakes in the } \\
\text { River Orb (and alluvial aquifer) by } \\
\text { other groundwater resources }\end{array}$ & 1.00 & 1.89 & 5 \\
\hline DS & $\begin{array}{l}\text { Substitution of water intakes in the } \\
\text { River Orb by desalinated water (coastal } \\
\text { municipalities) }\end{array}$ & 3.60 & 1.22 & 2 \\
\hline
\end{tabular}

Table 4: Main characteristics of the adaptation measures 


\begin{tabular}{|c|c|c|c|c|c|c|c|c|c|c|c|}
\hline Sub-basin & 01 & $\mathbf{O 2}$ & M4 & 04 & $\mathbf{J 3}$ & 05 & $\mathbf{V 3}$ & O6 & 08 & 010 & 012 \\
\hline Warm up & \multicolumn{11}{|c|}{ 1968-1969 } \\
\hline Calibration & \multicolumn{2}{|c|}{ 1970-2001 } & \multicolumn{2}{|c|}{ 1970-1992 } & \multicolumn{7}{|c|}{ 1970-2001 } \\
\hline $\operatorname{Nash}(\mathbf{Q})$ & 0.86 & 0.89 & 0.75 & 0.78 & 0.85 & 0.85 & 0.80 & 0.72 & 0.55 & 0.46 & 0.36 \\
\hline RMSE (mm) & 23.8 & 19.8 & 20.2 & 24.0 & 28.2 & 28.2 & 26.1 & 19.4 & 2.8 & 3.1 & 3.4 \\
\hline Validation & \multicolumn{2}{|c|}{ 2002-2007 } & \multicolumn{2}{|c|}{ 1993-1995 } & \multicolumn{7}{|c|}{$2002-2007$} \\
\hline $\operatorname{Nash}(\mathbf{Q})$ & 0.93 & 0.80 & 0.47 & 0.54 & 0.80 & 0.72 & 0.78 & 0.40 & 0.69 & 0.58 & 0.40 \\
\hline RMSE (mm) & 16.5 & 29.3 & 42.1 & 50.5 & 29.8 & 1.8 & 25.5 & 20.8 & 1.7 & 2.0 & 2.4 \\
\hline
\end{tabular}

Table A: Calibration and validation performances of the hydrological model by sub-basins. 

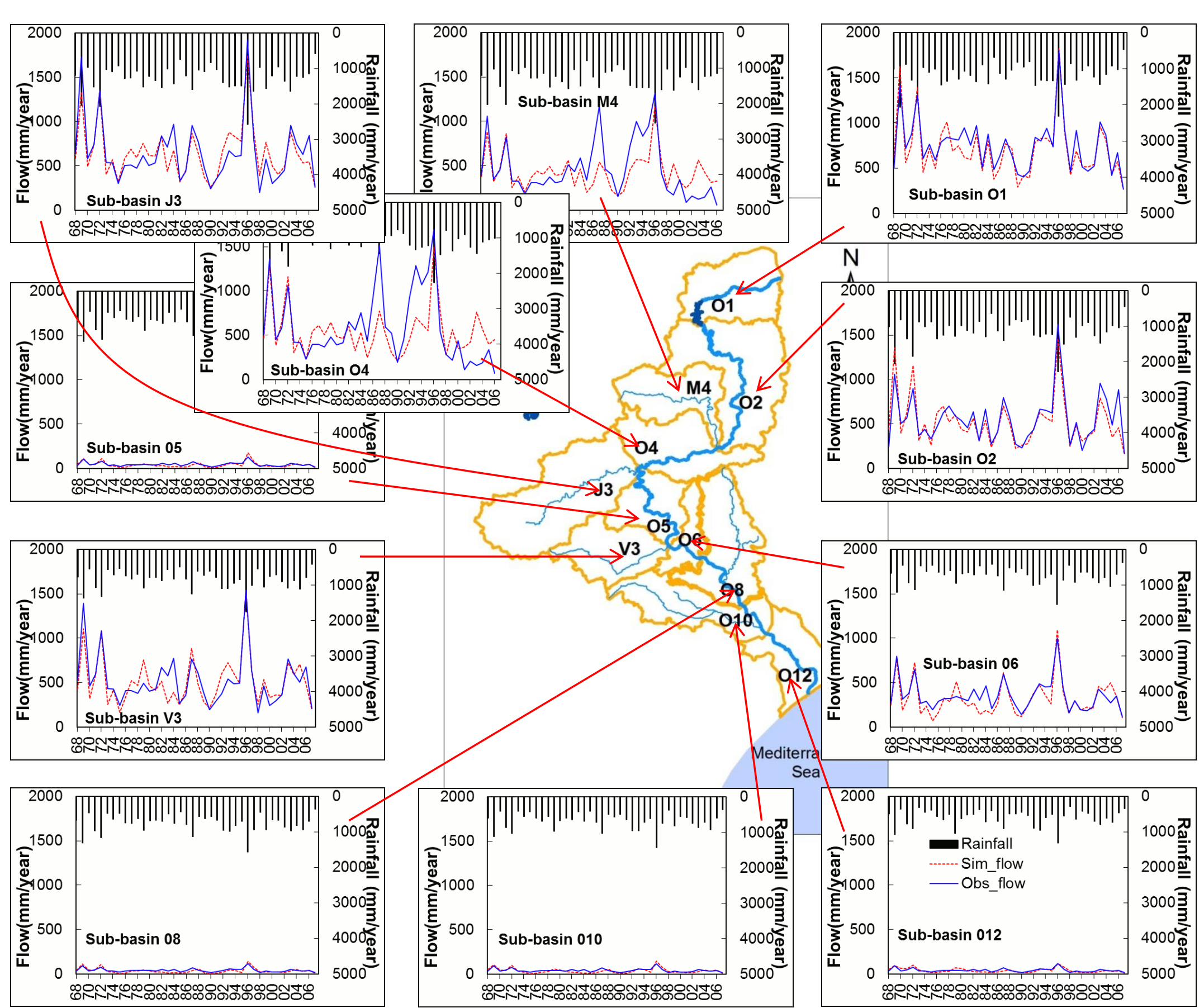